\title{
黑 Springer
}

Chinese Society of Pavement Engineering

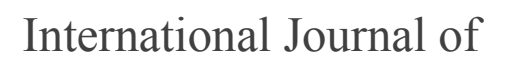

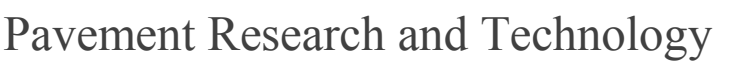

Journal homepage: www.springer.com/42947

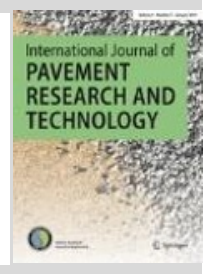

Recent advances in characterizing the "bee" structures

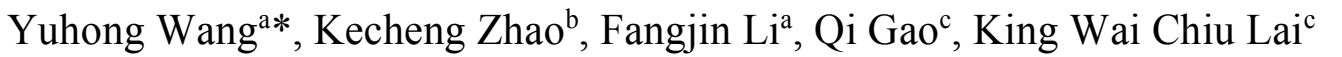 \\ Dept. of Civil and Environmental Engineering, The Hong Kong Polytechnic University, Hong Kong SAR, China \\ Zhejiang Communications Construction Group Co., Ltd., Zhejiang Province, China \\ Dept. of Biomedical Engineering, Centre for Robotics and Automation, City University of Hong Kong, Hong Kong SAR, China
}

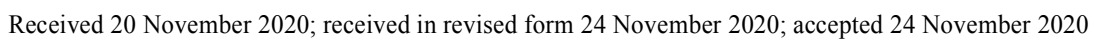

\begin{abstract}

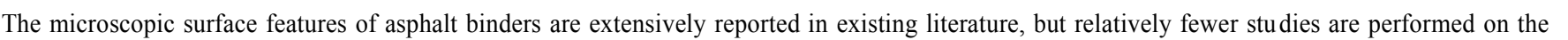

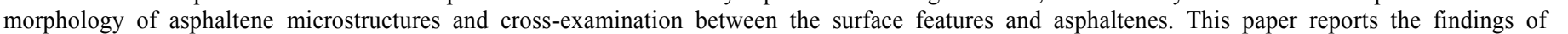

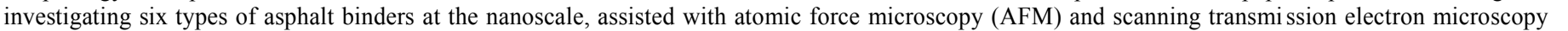
प

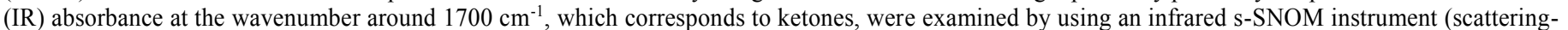
प

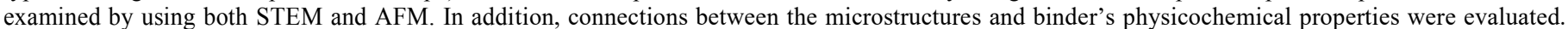

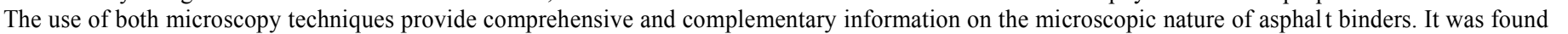

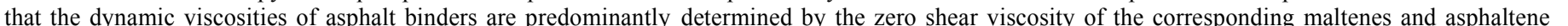

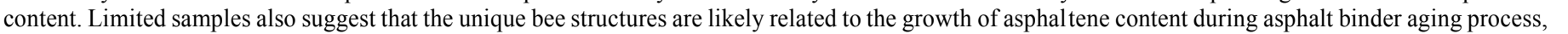

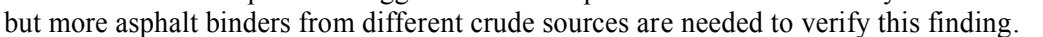

$\square$

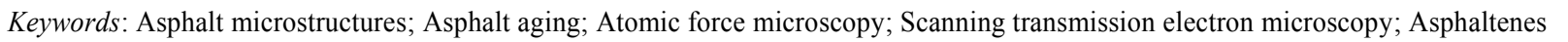

\section{Introduction}

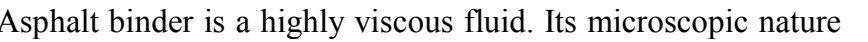

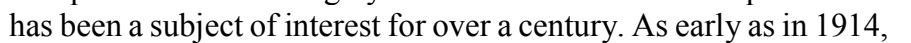

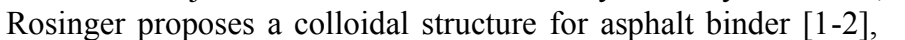

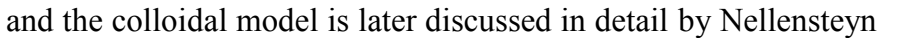

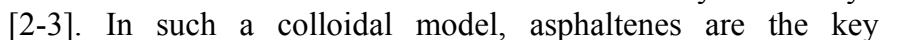

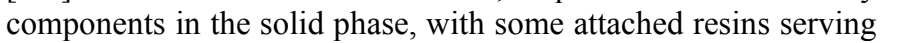

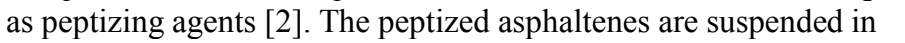

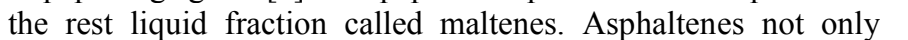

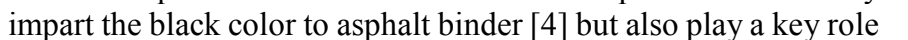
in asphalt binder's rheological properties. More specifically, asphaltenes are the "thickeners" that drive up the viscosity of

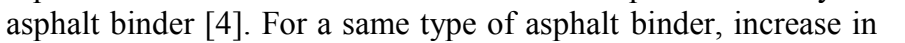

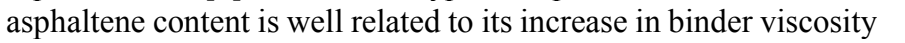

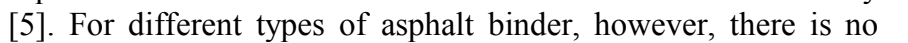

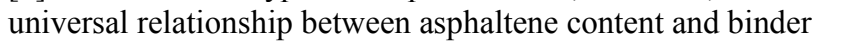

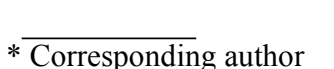

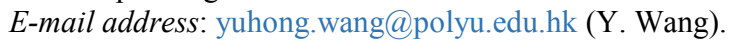

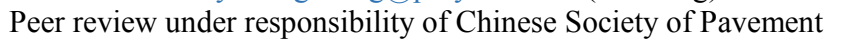
पणाणमाणाए

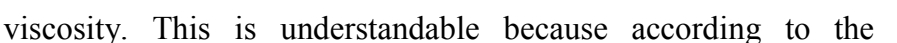

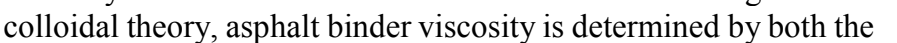

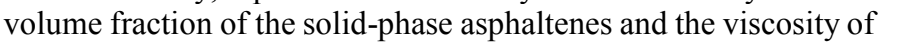

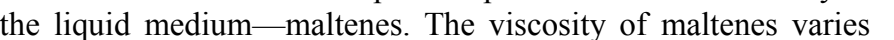

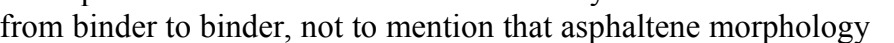

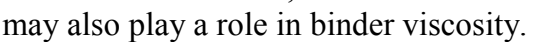

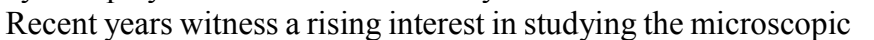

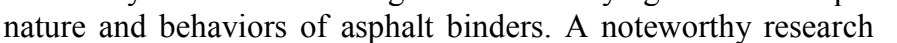

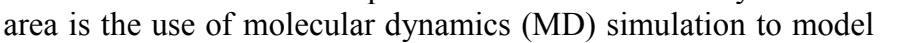

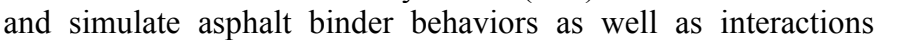

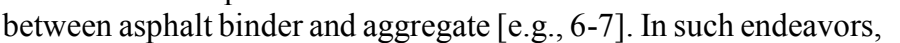

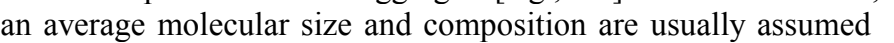

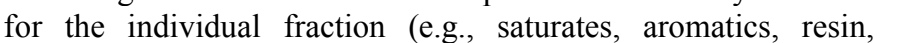

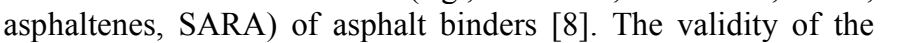

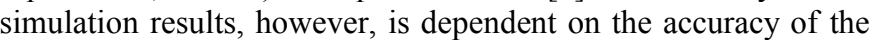

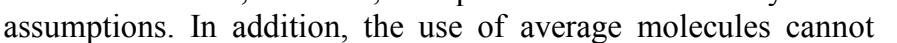

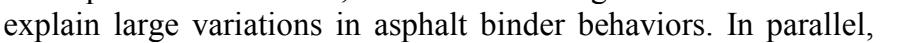

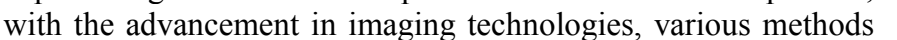

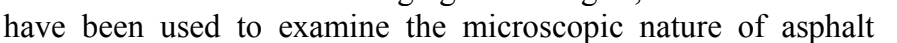

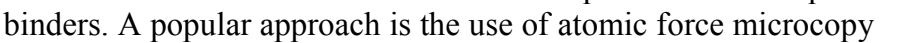

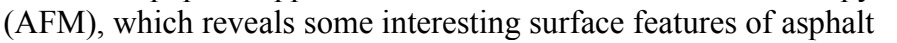
binders. Perhaps the most notable surface feature is the "bee" 


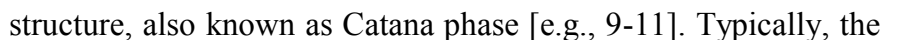

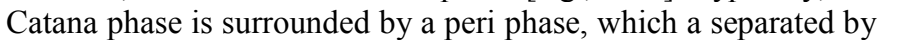

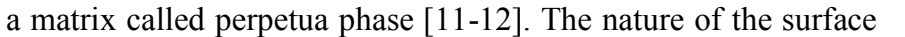
feature, particularly the "bee" structure, is subject to many

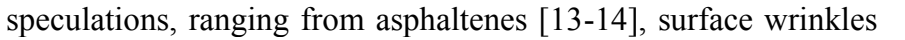

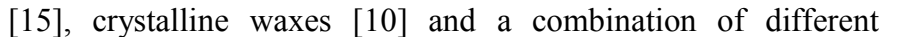

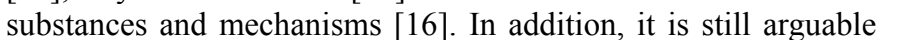

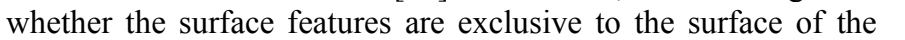

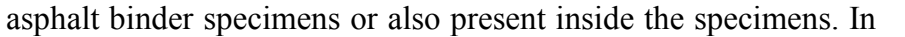

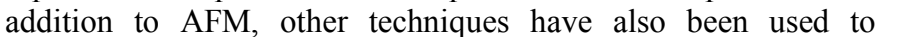

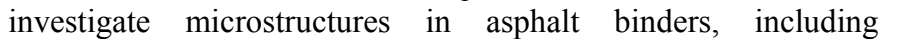

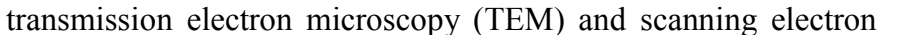

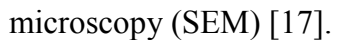

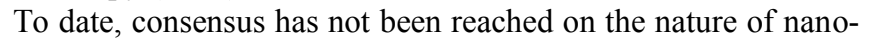

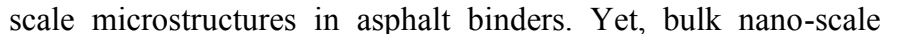

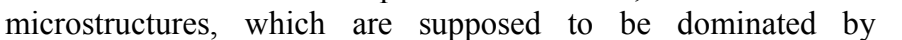

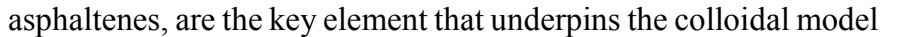

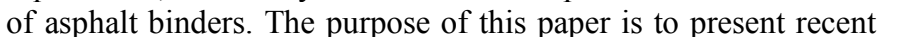

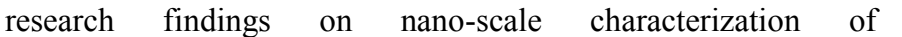

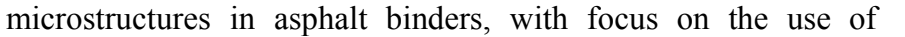

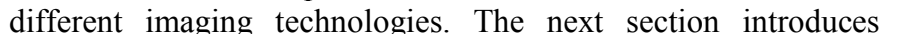

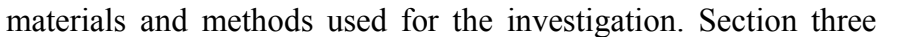

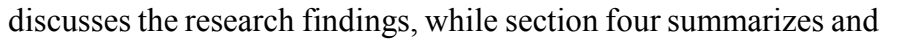

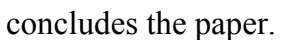

\section{Materials and method}

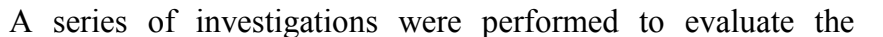

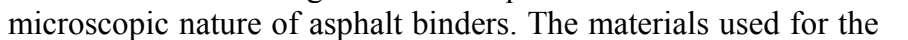

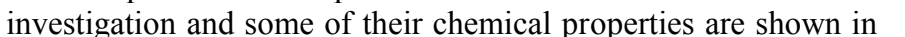

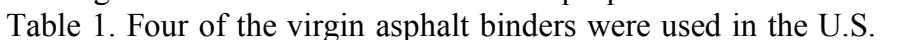

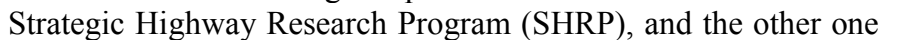

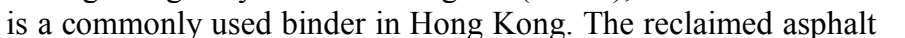

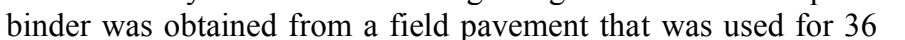

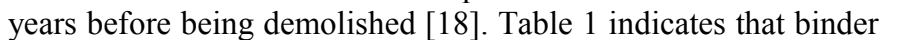

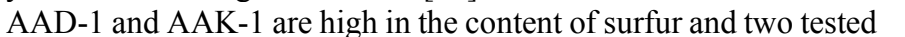

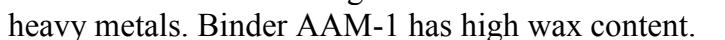

Different methods were used in this study to examine the "bee"

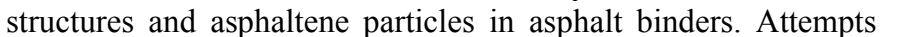

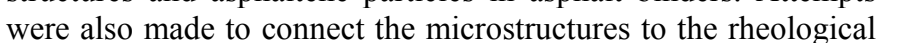

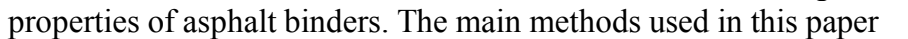

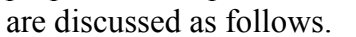

\subsection{Examination of surface microstructures and features using $A F M$ and $A F M-I R$}

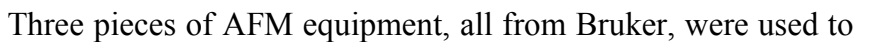

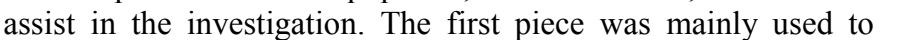

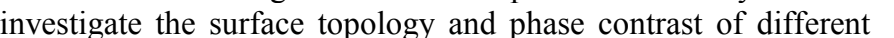

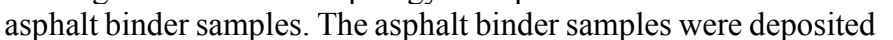

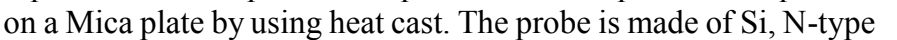

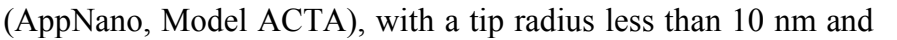
height between 14 and $16 \mu \mathrm{m}$ [20]. The second piece (BioScope

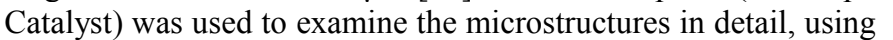

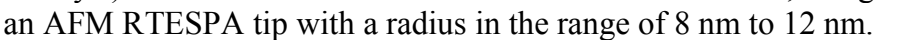

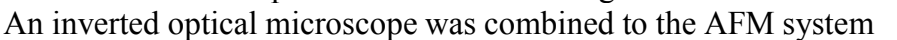

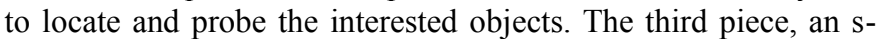

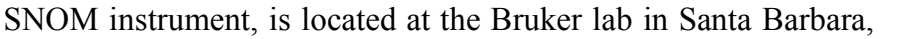

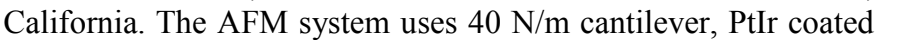

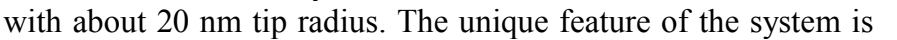

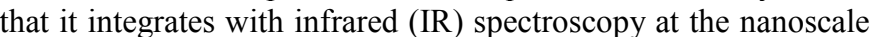

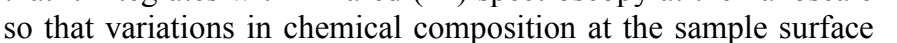
पालापाणाणाप

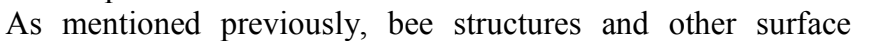

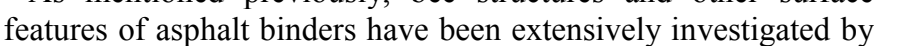

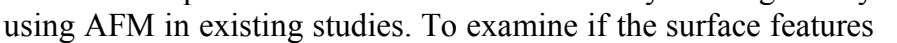

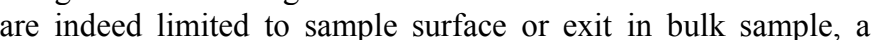

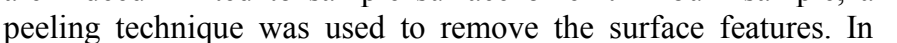

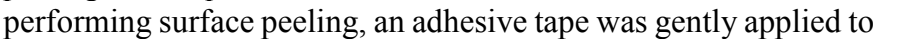
ए

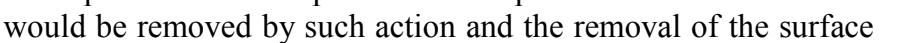

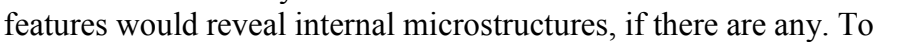

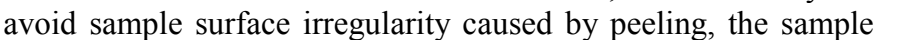

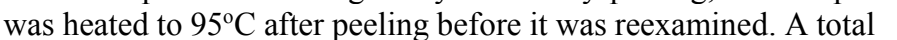

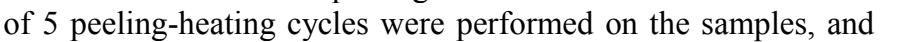

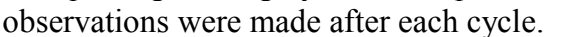

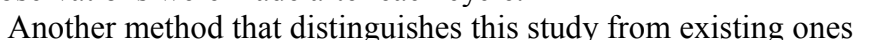

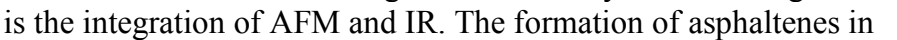

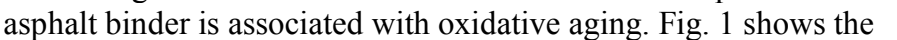

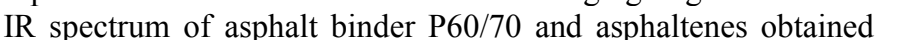

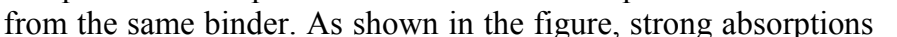

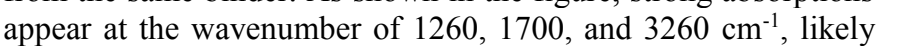

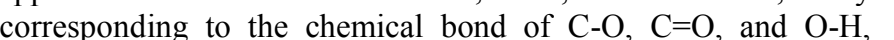

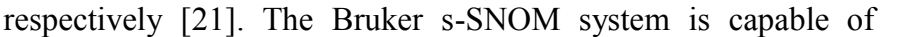

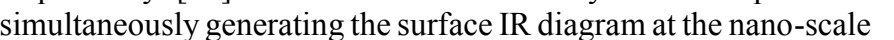

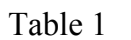

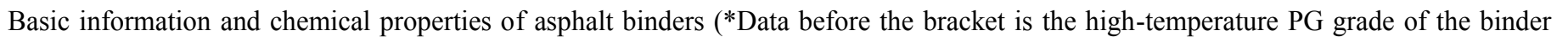

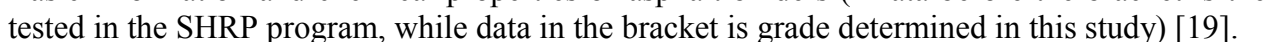

\begin{tabular}{|c|c|c|c|c|c|c|}
\hline \multirow[t]{3}{*}{ 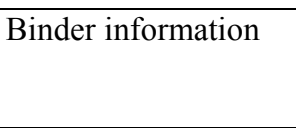 } & \multicolumn{6}{|c|}{ 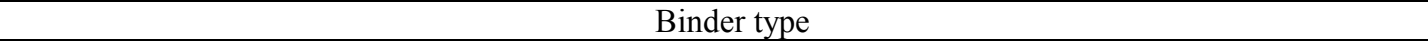 } \\
\hline & \multicolumn{5}{|l|}{ 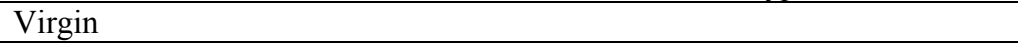 } & \multirow{2}{*}{ 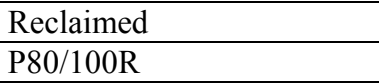 } \\
\hline & 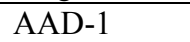 & पिमाप & पिमाण & पिएा & 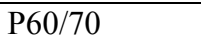 & \\
\hline \multirow{3}{*}{ 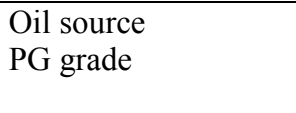 } & 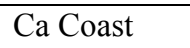 & 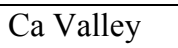 & 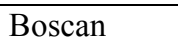 & 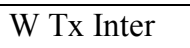 & 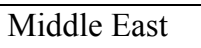 & 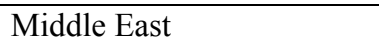 \\
\hline & $\square\|\| \square \| \square \square \square$ & पाणाणए & पाणाणाए & 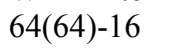 & $\square\|\| \square$ & $\square \square \square \square \square$ \\
\hline & & & & & & 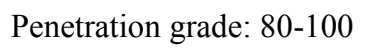 \\
\hline$\square \square \square$ & $\square \square$ & $\square \square$ & $\square \square$ & $\square \square \square$ & $\square$ & $\square$ \\
\hline$\square \square \square$ & $\square \square$ & $\square \square$ & $\square \square$ & $\square \square$ & $\square$ & $\square$ \\
\hline 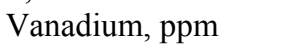 & $\square \square$ & $\square \square$ & $\square 1 \square$ & $\square$ & $\square$ & $\square$ \\
\hline 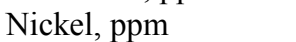 & $\square \square$ & $\square \square$ & $\square 1 \square$ & $\square \square$ & $\square$ & $\square$ \\
\hline 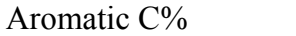 & $\square \square$ & $\square \square$ & 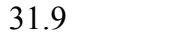 & $\square \square$ & $\square$ & $\square$ \\
\hline 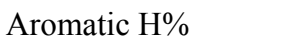 & 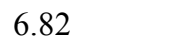 & पाण & 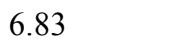 & $\square \mathrm{पाण}$ & $\square$ & $\square$ \\
\hline$\square \square \square \square$ & 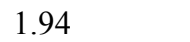 & $\square \square \square$ & 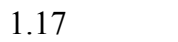 & 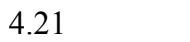 & $\square \square$ & 미 \\
\hline
\end{tabular}




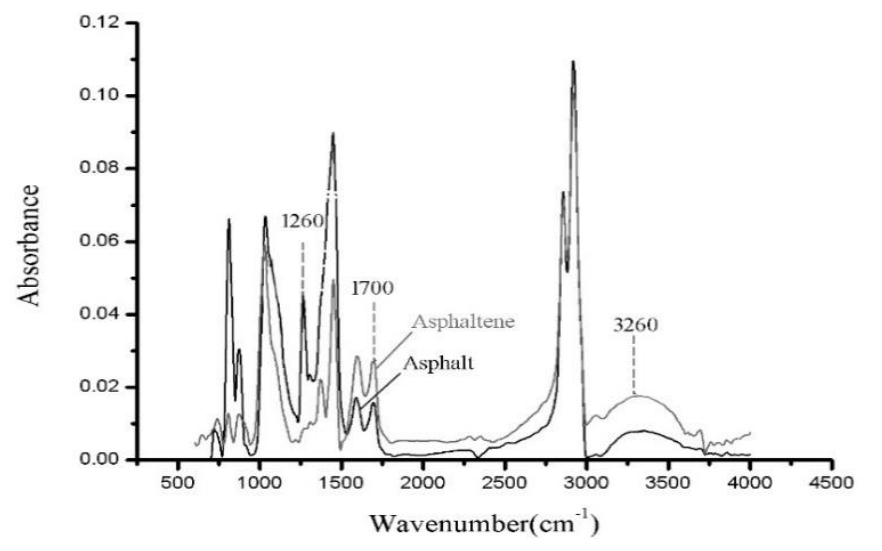

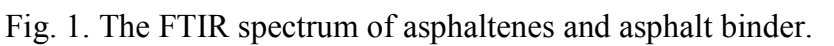

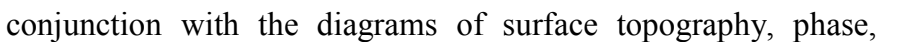

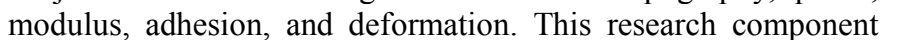

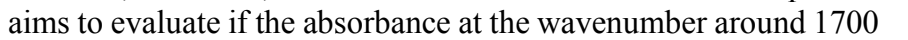
口ण

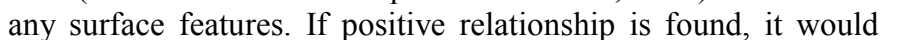

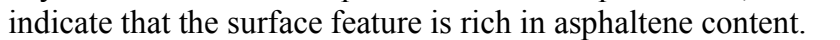

\subsection{Examination of internal microstructures using STEM and cross-examination of microstructures using STEM and AFM}

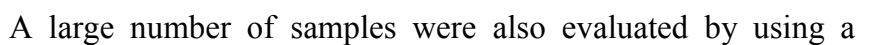

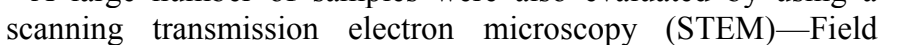

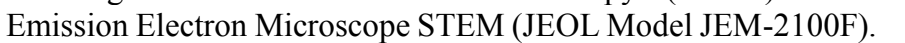

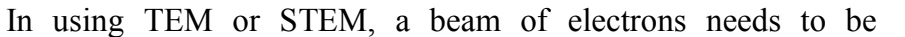

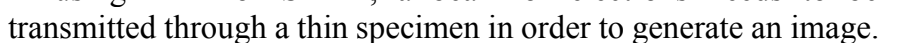

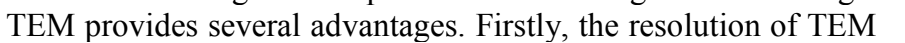

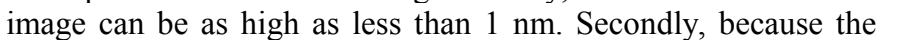

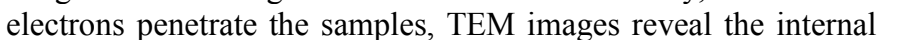

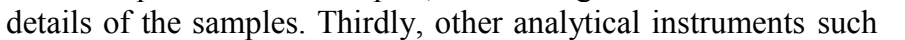

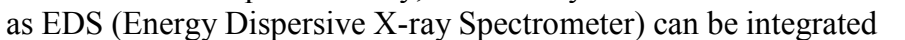

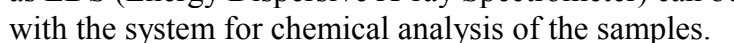

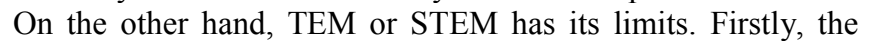

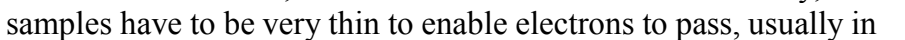
पा

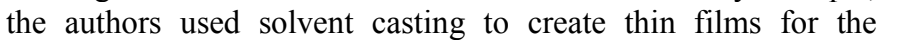

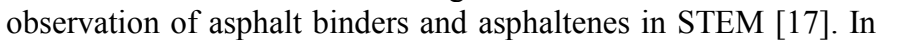

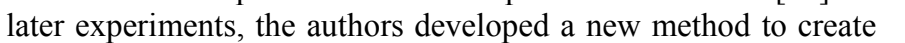

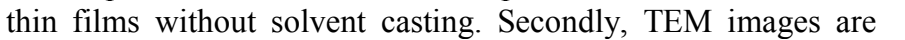

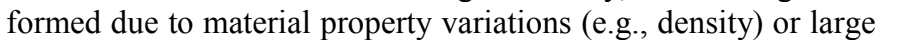

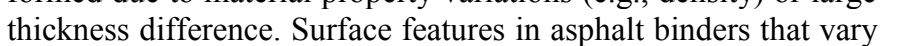

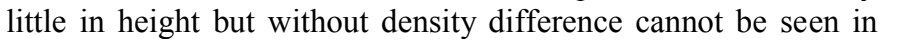

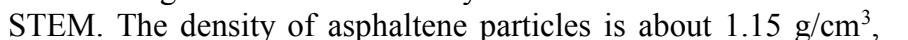

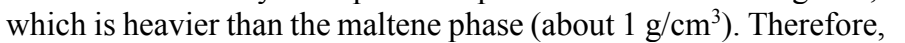

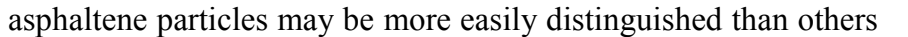

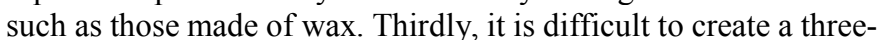

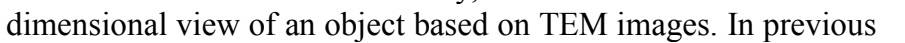

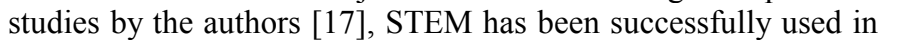

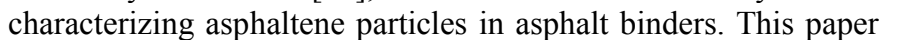

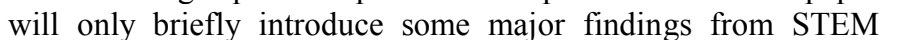

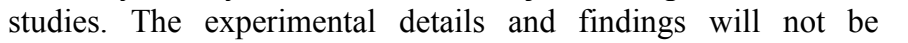
पणाणाणाण

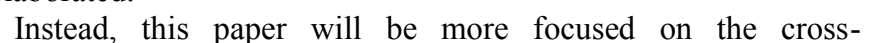

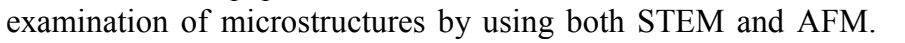

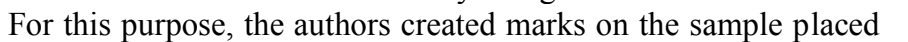

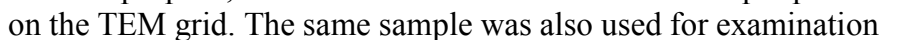

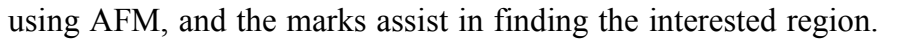

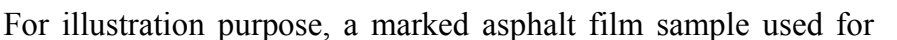

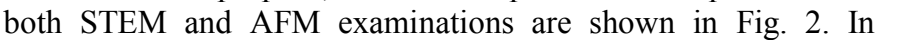

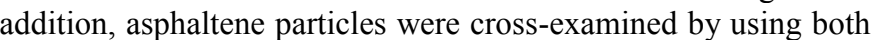

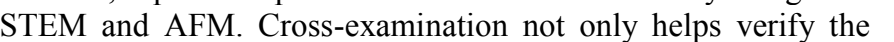

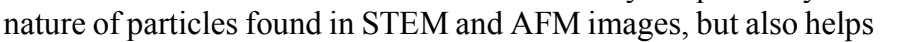

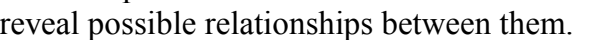

\subsection{Aging treatment and rheological tests}

While the images of "bee" structures and asphaltene articles shed

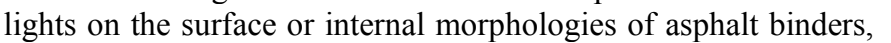
ए

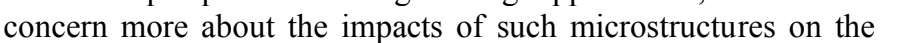

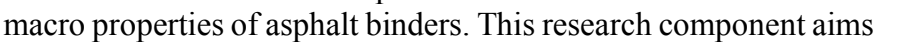

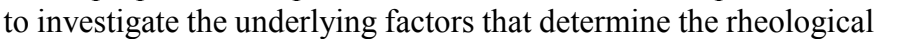

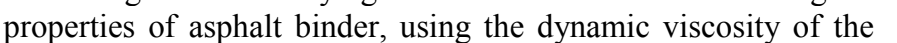

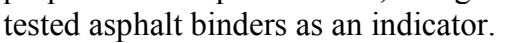

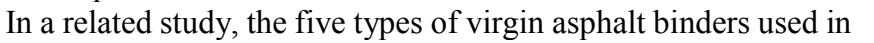

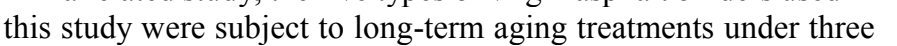

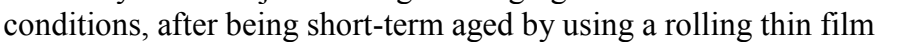

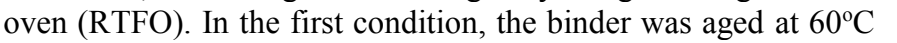

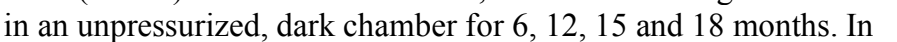

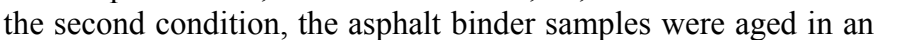

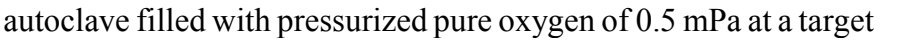

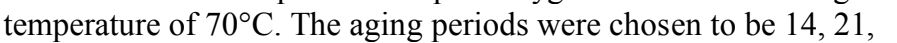

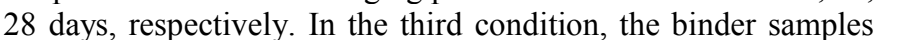

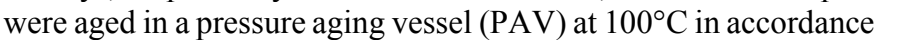

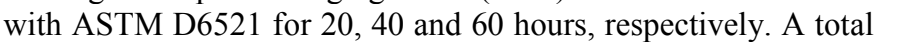

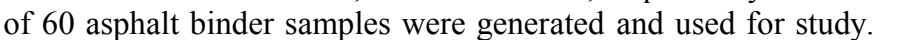

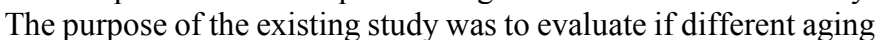

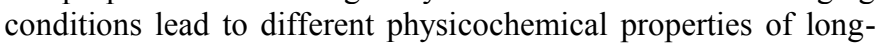

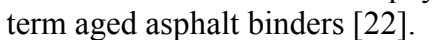

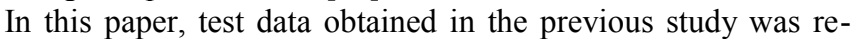
$\square\|\| \|$ to evaluate factors that affect binder's dynamic viscosity,

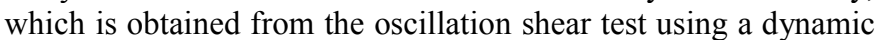

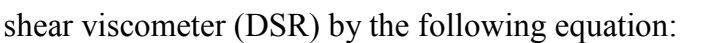

$\eta^{\prime}=\frac{G^{\prime \prime}}{\omega} \square$

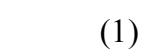

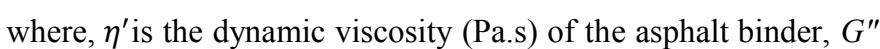
is the loss modulus $(\mathrm{Pa})$, and $\omega$ is loading frequency $(\mathrm{rad} / \mathrm{s})$. $\square$

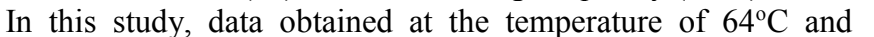

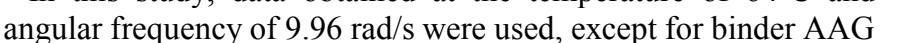

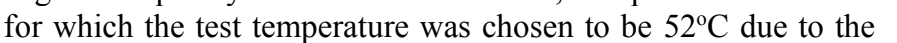

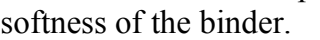

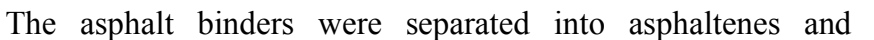

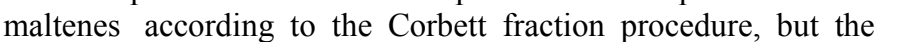

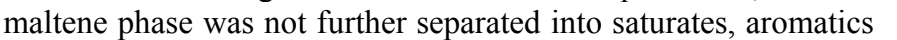

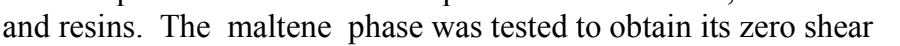

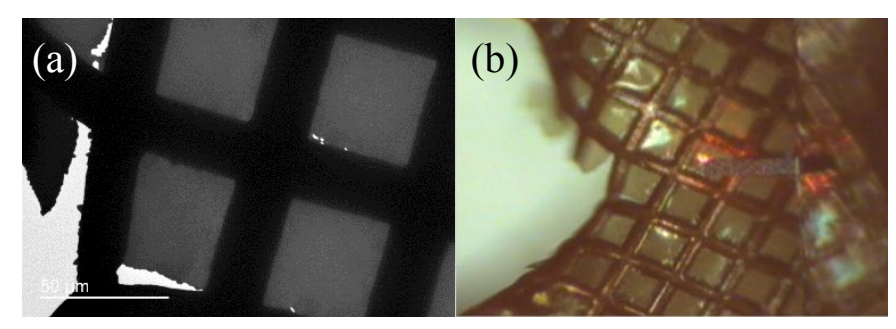

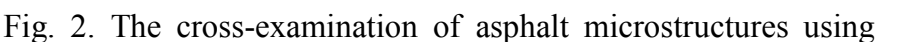

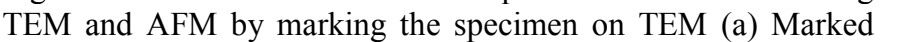

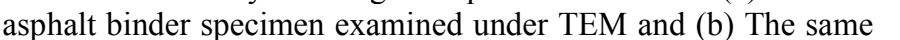

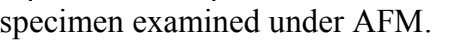




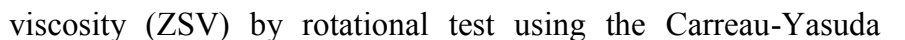

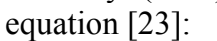

$\frac{\eta(\dot{\gamma})-\eta_{\infty}}{\eta_{0}-\eta_{\infty}}=\frac{1}{\left(1+(\lambda \cdot \dot{\gamma})^{\frac{1-p}{p_{1}}}\right.} \square$

एणाएणाणाए

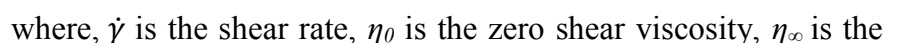

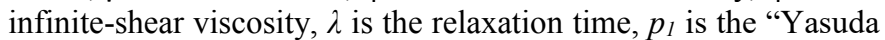

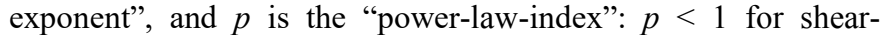

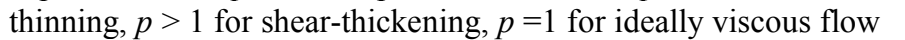

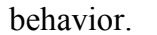

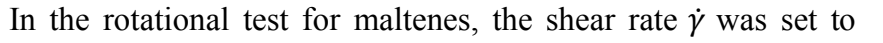

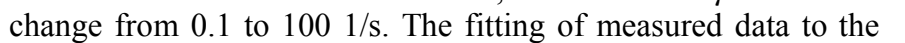

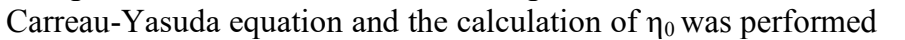

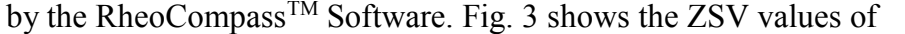

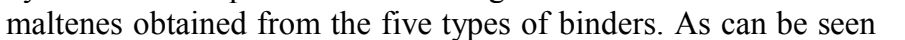

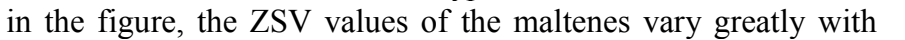

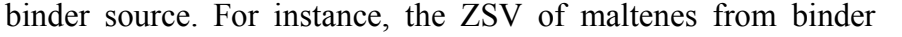

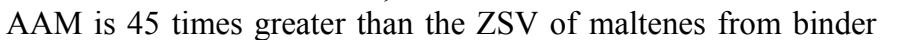
प्रणा

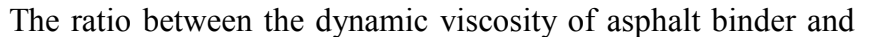

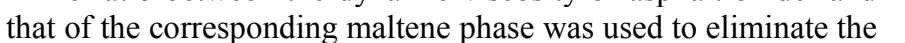

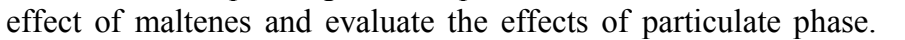
However, data on the dynamic viscosity of maltenes $(\omega=9.96 \mathrm{rad} / \mathrm{s})$

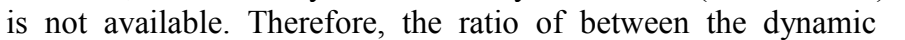

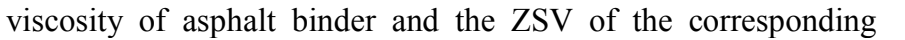

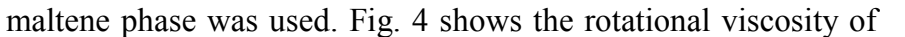

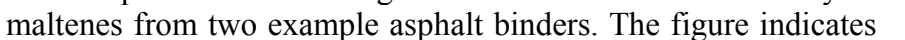
प

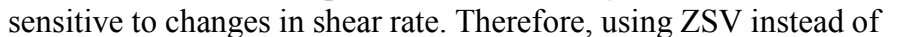

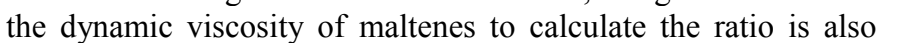

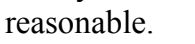

\section{Results and discussion}

\subsection{Changes in the surface features of asphalt binders}

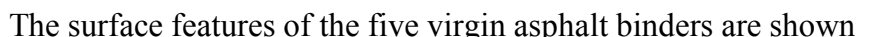

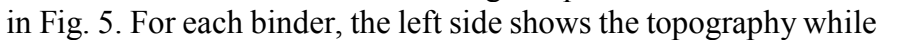

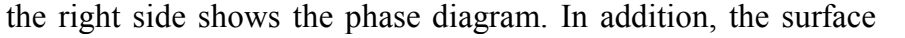

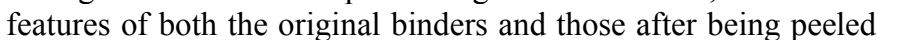

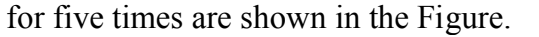

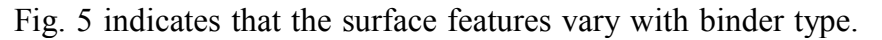
For binder P60/70, the "bee" structures are noticeable, but the

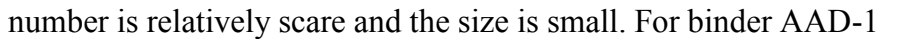

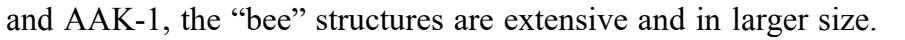
\begin{tabular}{ll|l|l|l|l|} 
&
\end{tabular}

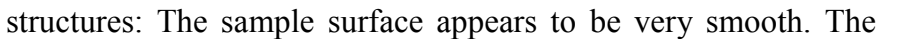

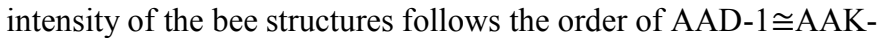

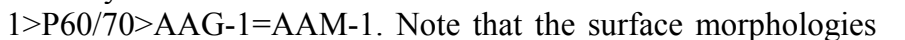

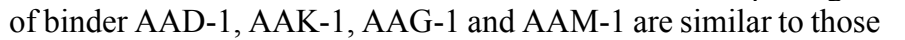

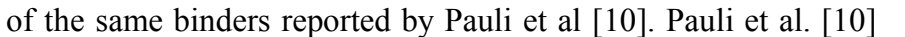

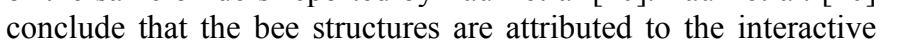

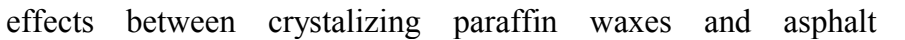

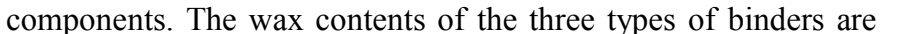

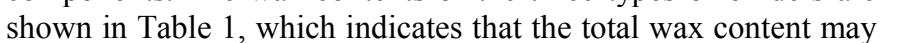
प

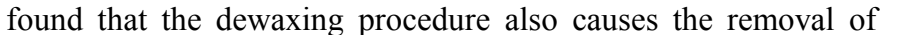

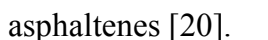

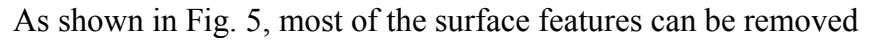

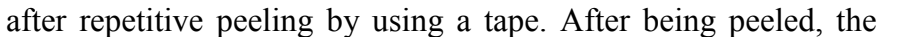

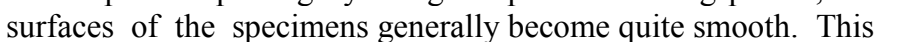

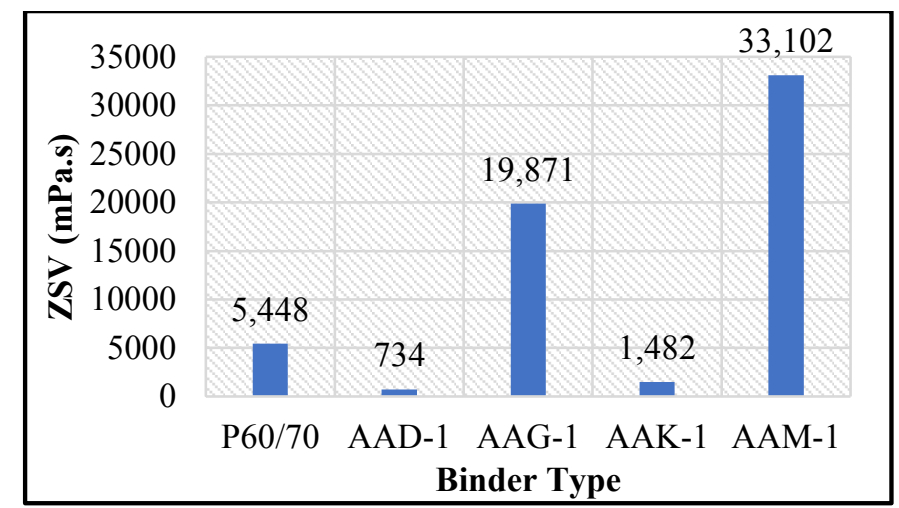

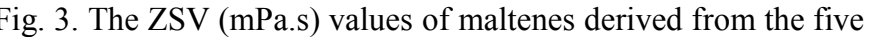

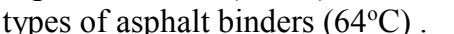

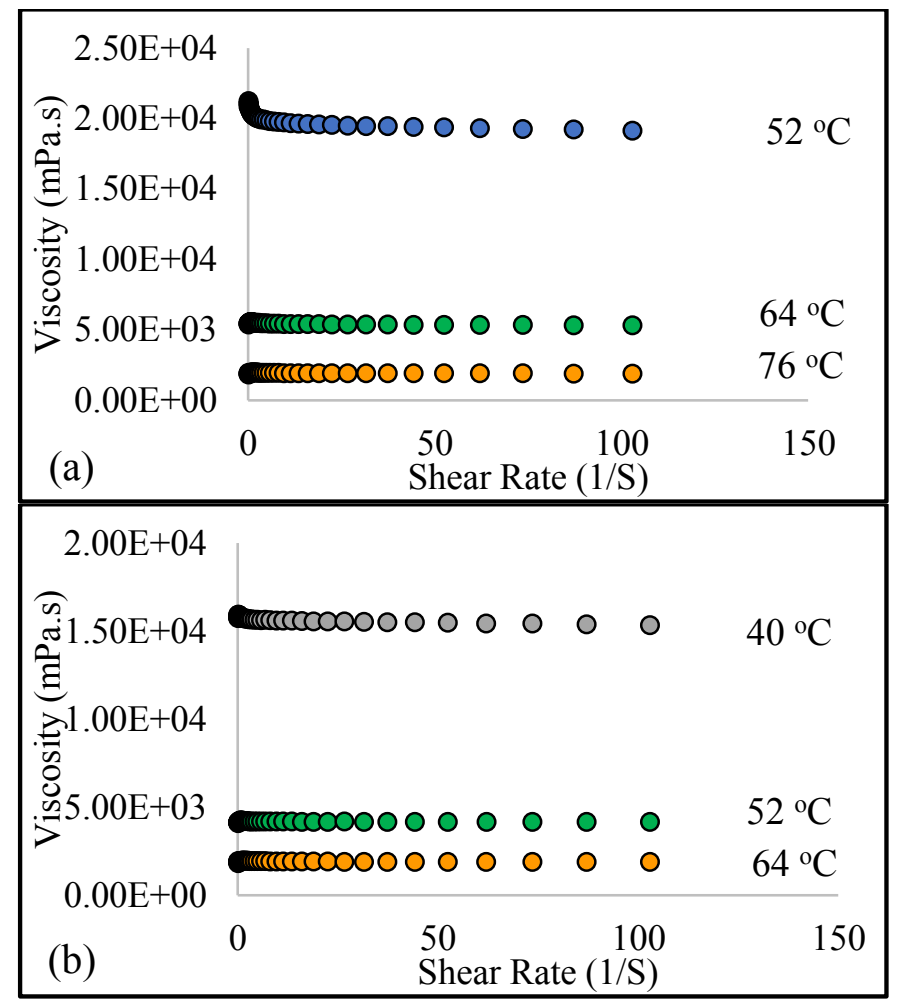

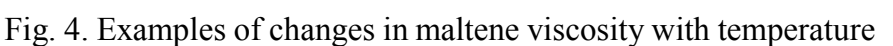

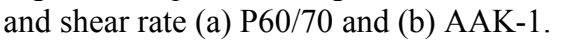

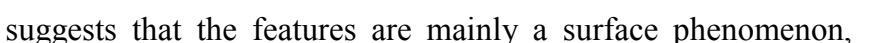

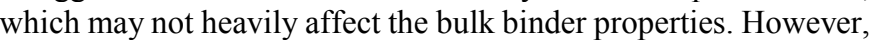
पा |

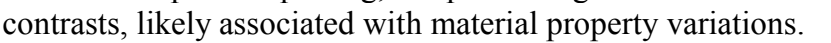

\subsection{Relationships between surface features and NanoIR absorption}

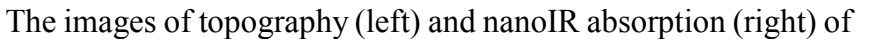

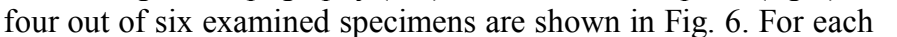

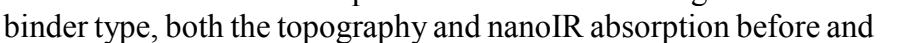

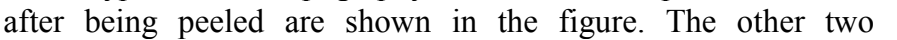

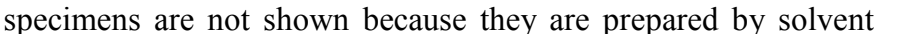

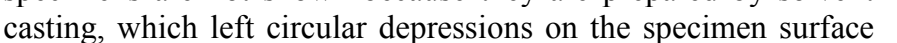
ए 

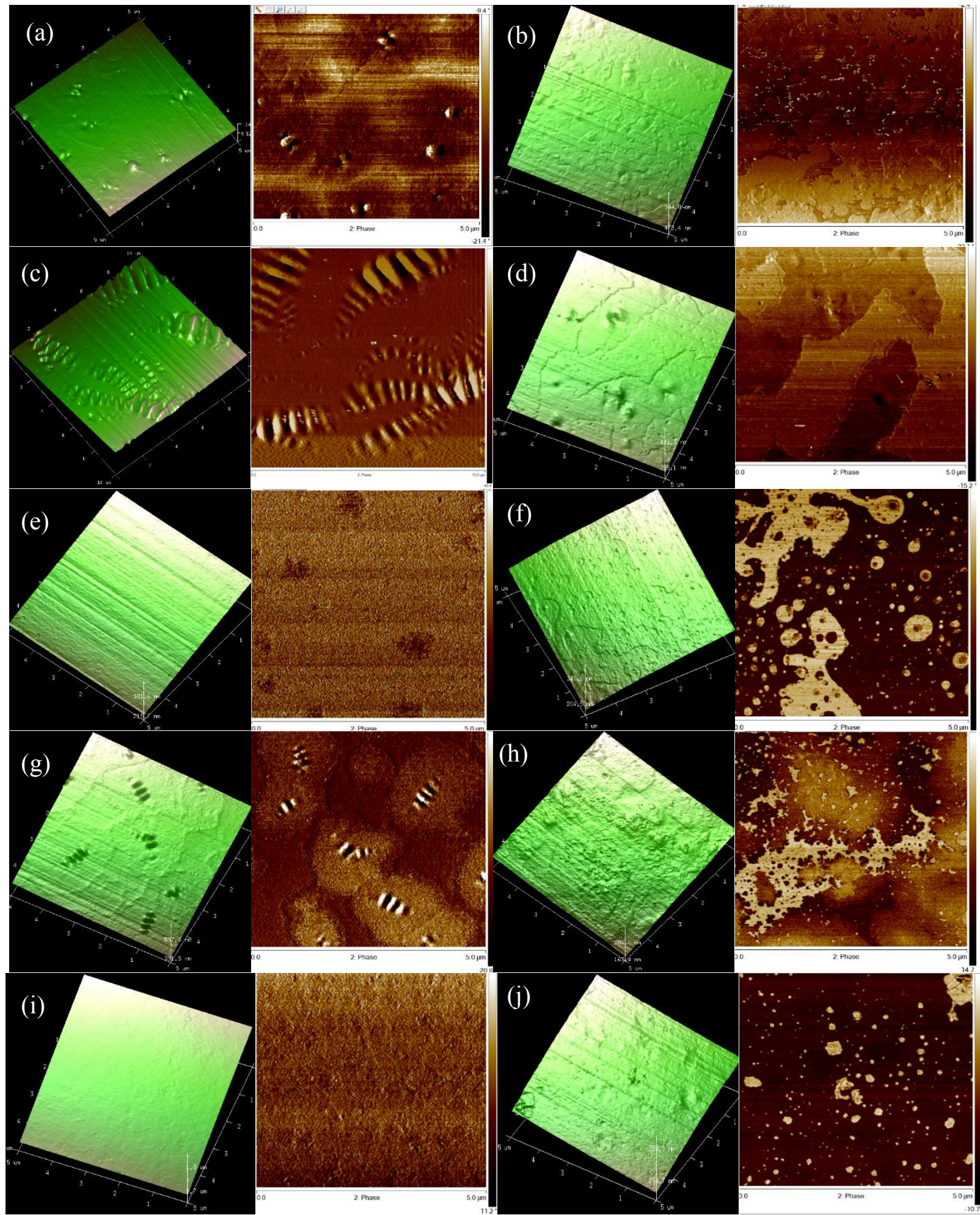

Fig. 5.

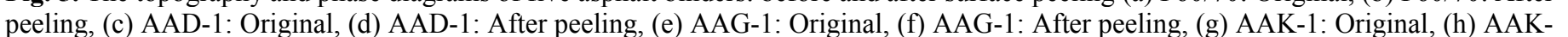

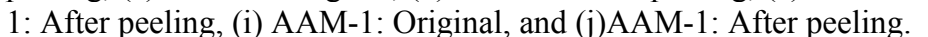

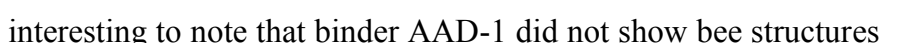

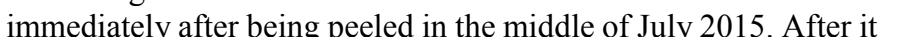
was sent to the Bruker's lab in California and tested in November

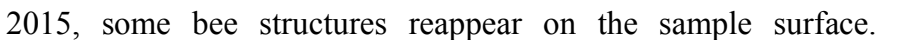

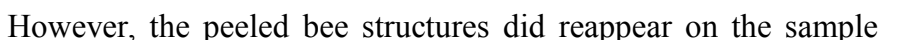

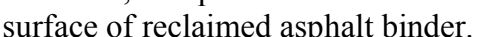

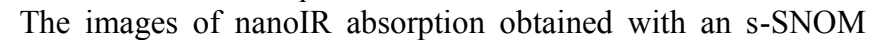

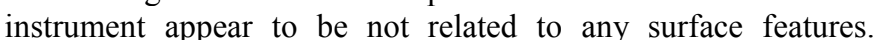


$\square$

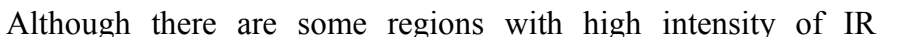

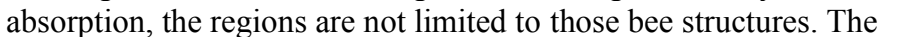

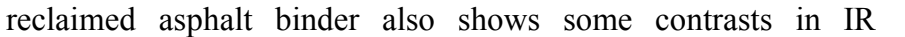

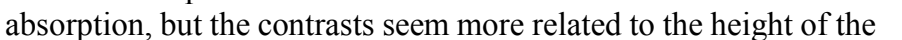

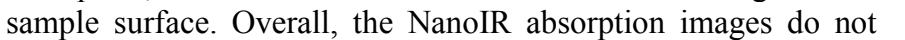

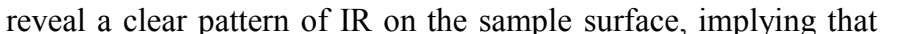

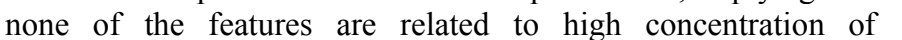

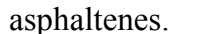

\subsection{STEM images}

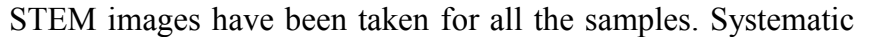

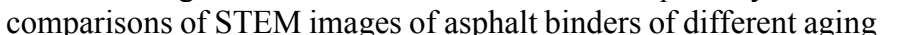

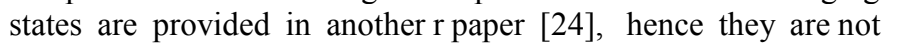
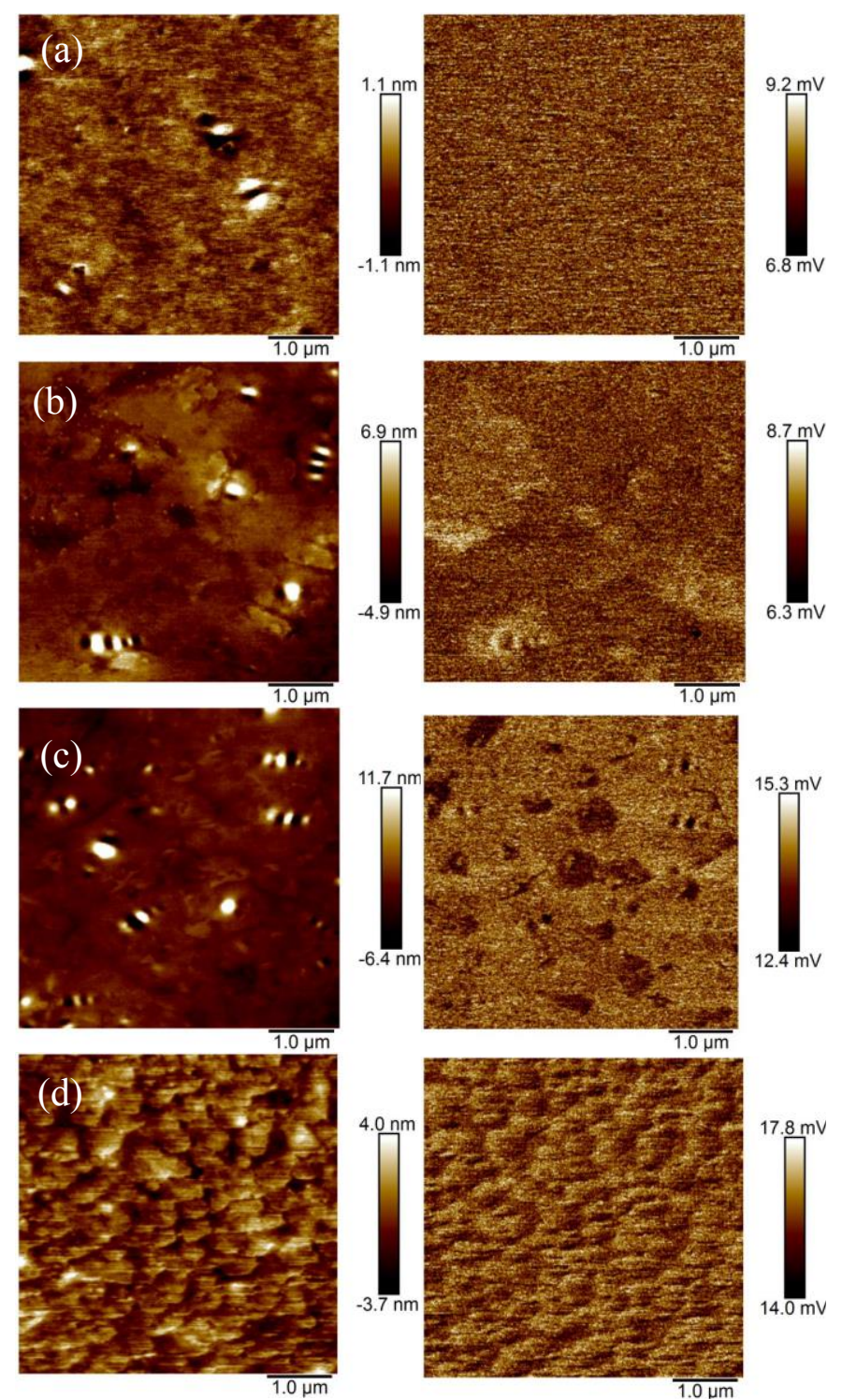

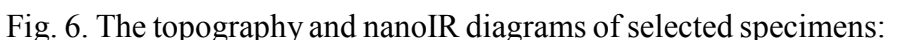

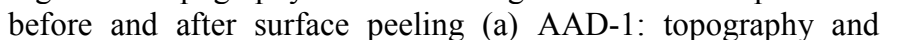

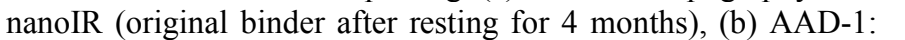

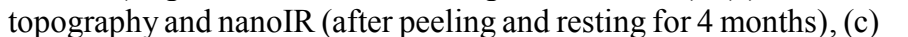

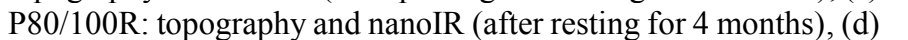

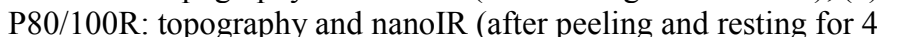

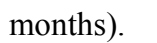

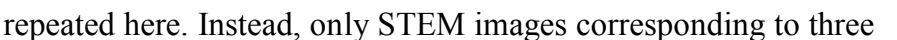

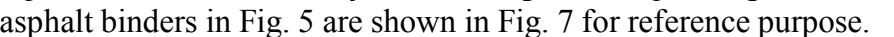

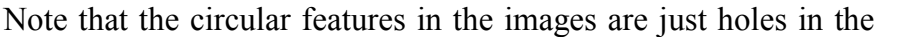

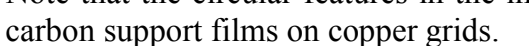

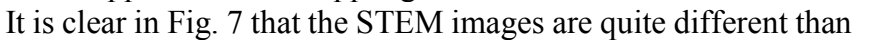

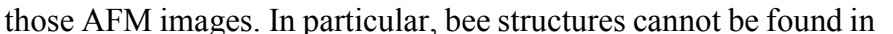

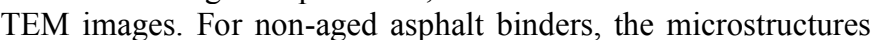

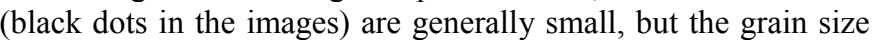

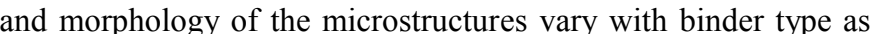

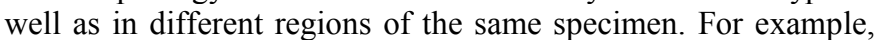

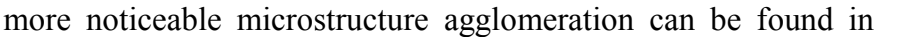

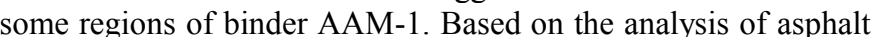

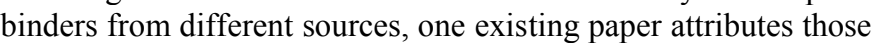

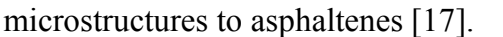

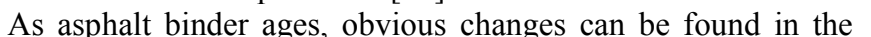

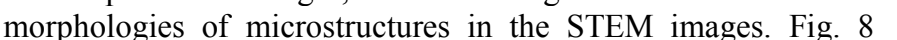

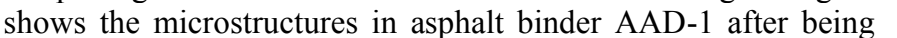

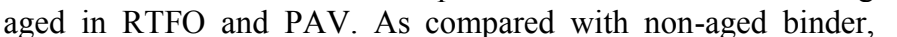

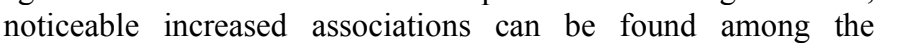

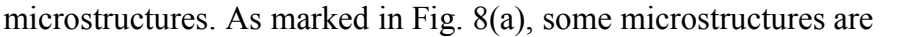

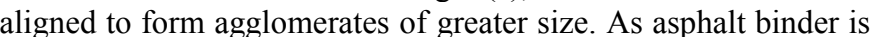

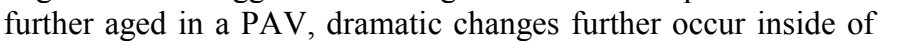

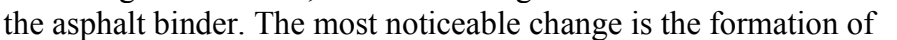

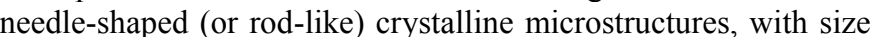

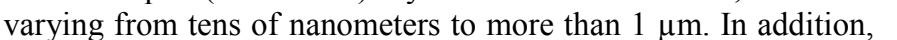

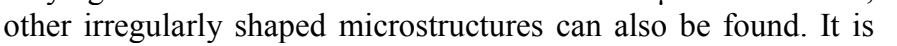

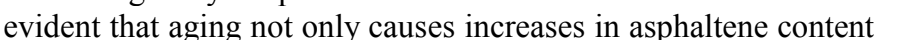

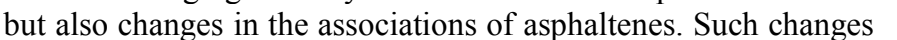

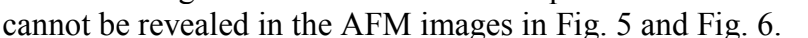

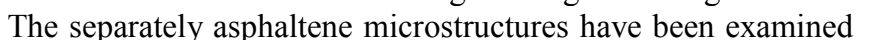

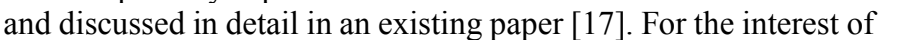

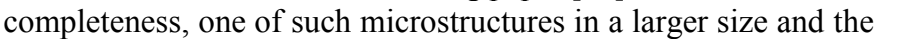

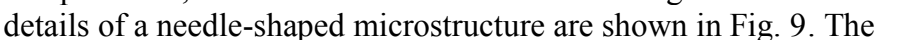

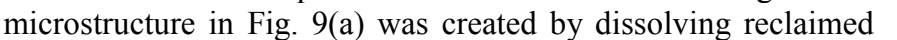

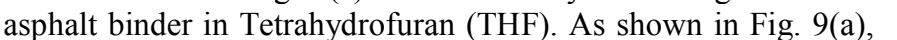

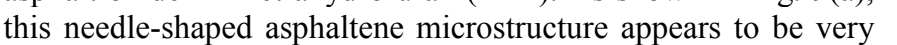

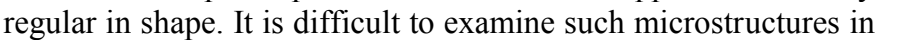

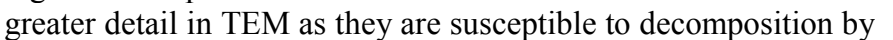

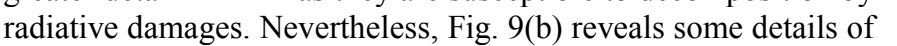

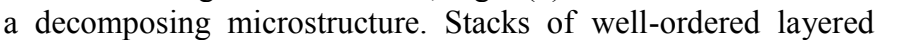

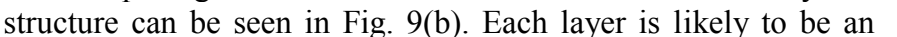
individual asphaltene molecule's aromatic sheet, which is stacked

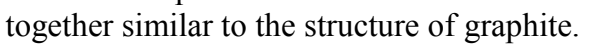

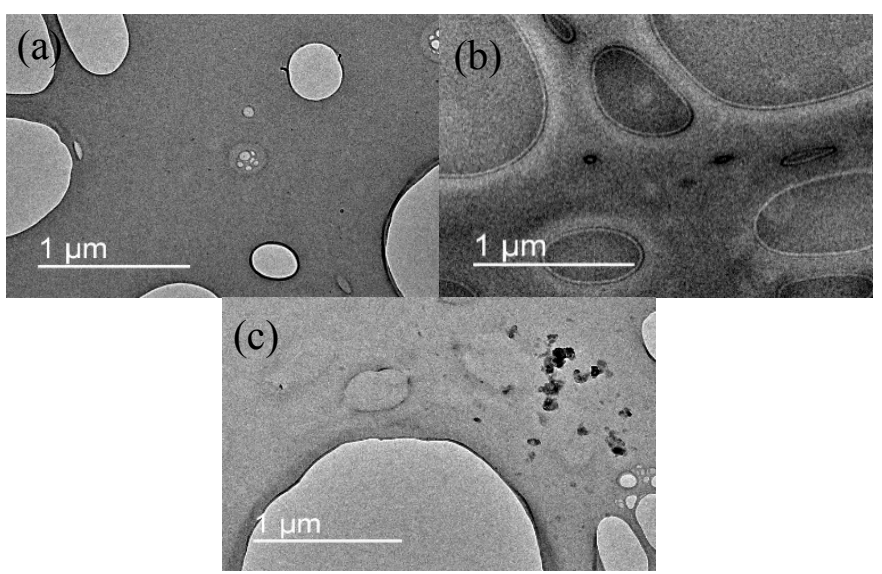

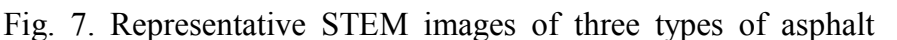

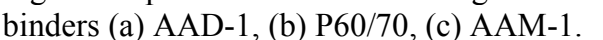




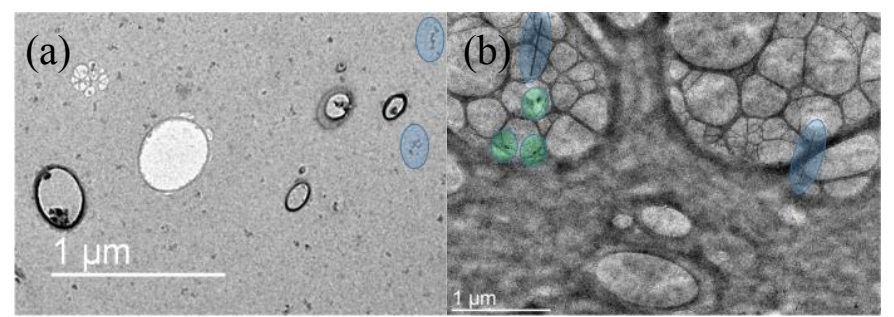

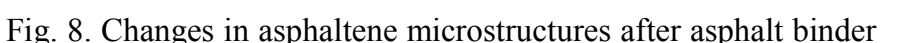

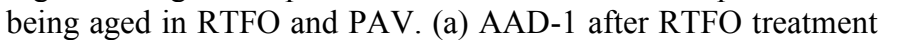

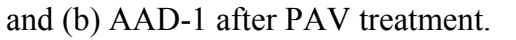

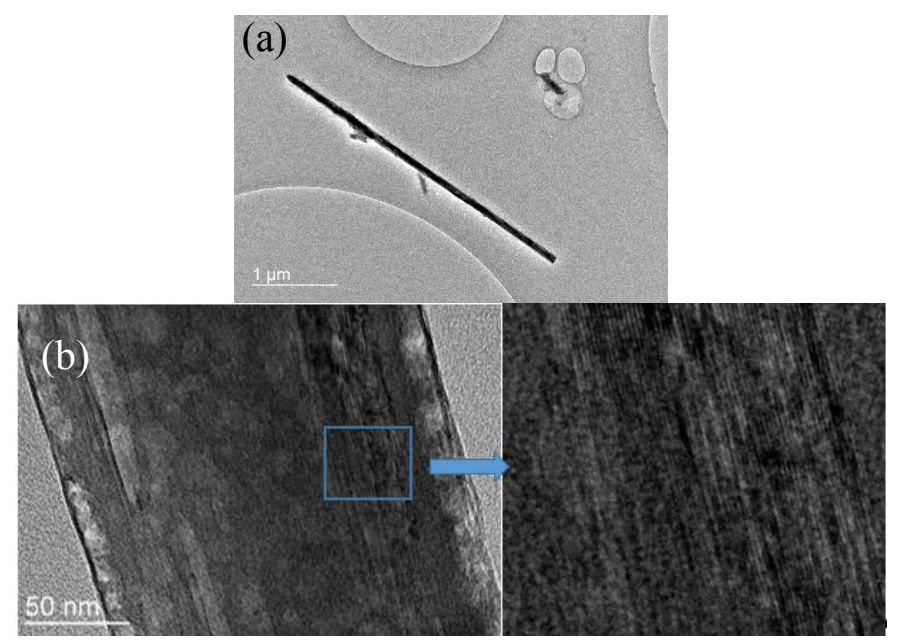

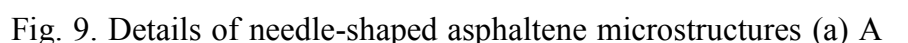

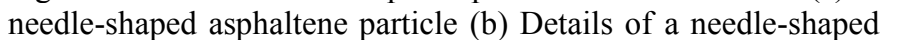

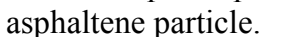

\subsection{Cross examination of bee structures and asphaltene particles in AFM and STEM}

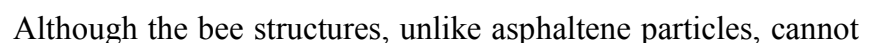

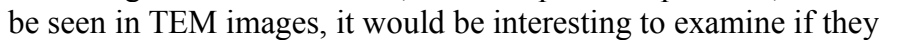

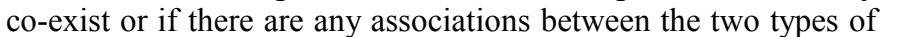

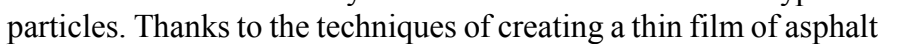

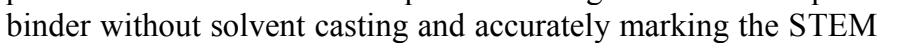

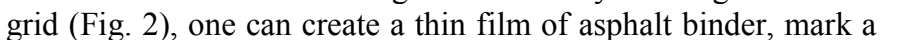

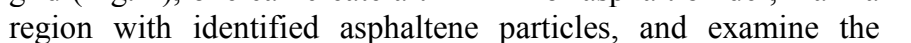

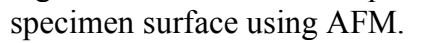

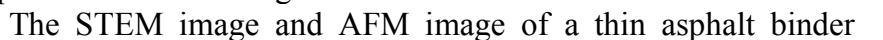

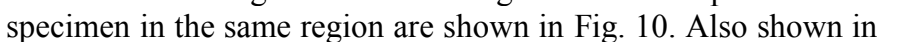

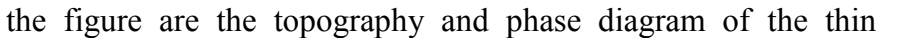

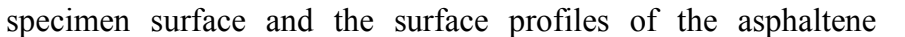

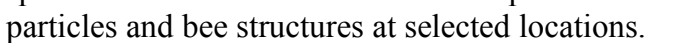

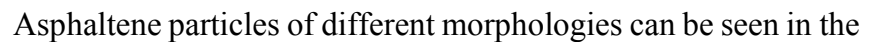

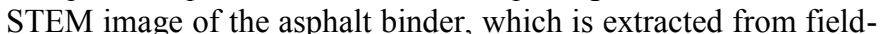

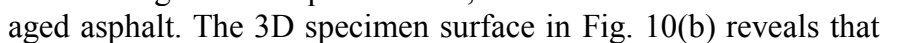

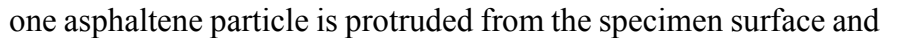

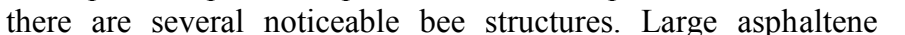

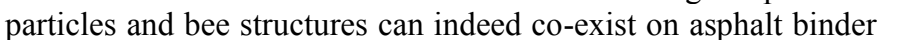

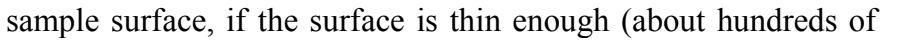

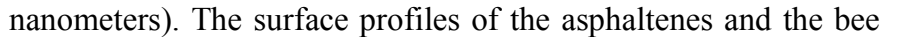

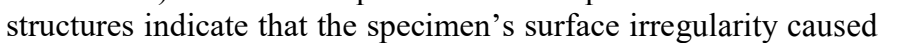

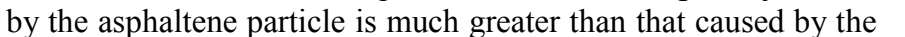

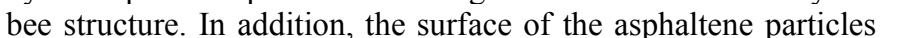

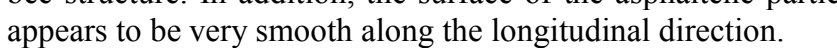

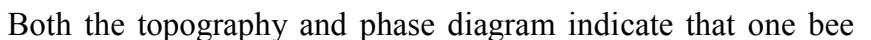

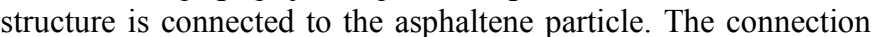

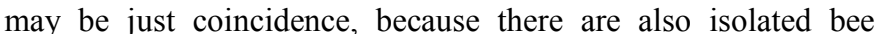

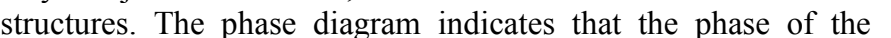

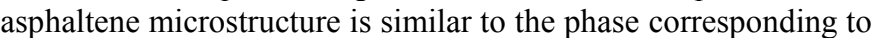

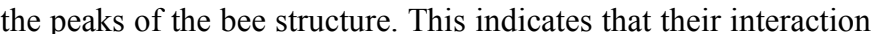

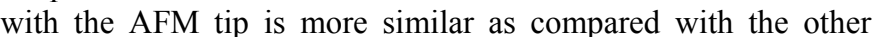

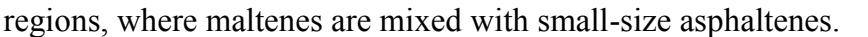

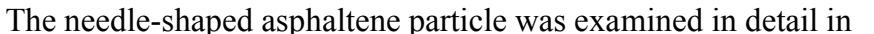

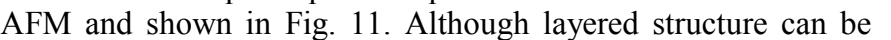

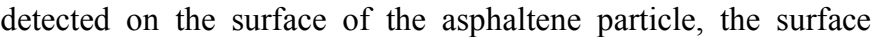

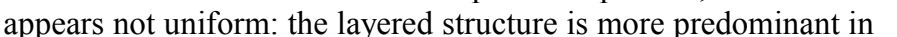

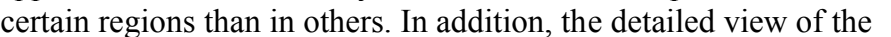
ए

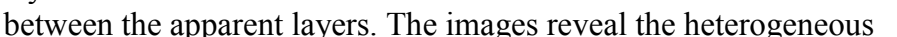

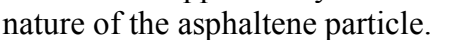

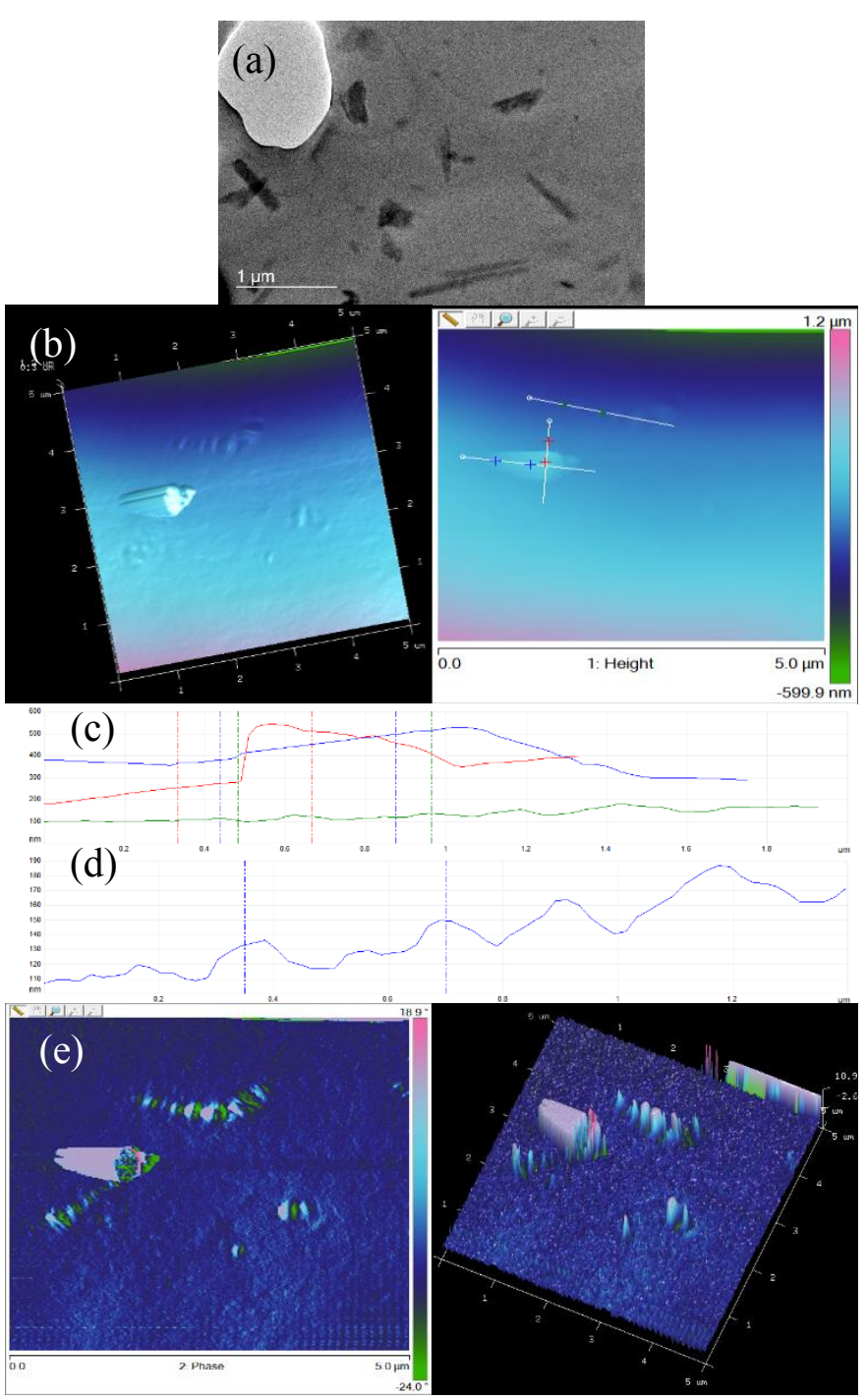

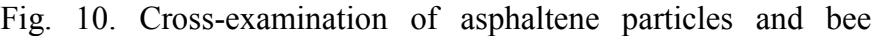

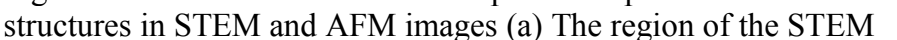

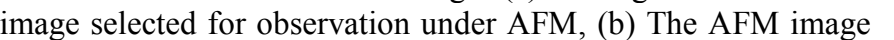

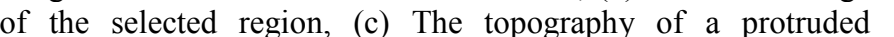

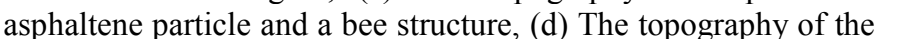

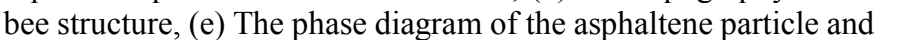

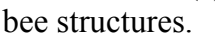



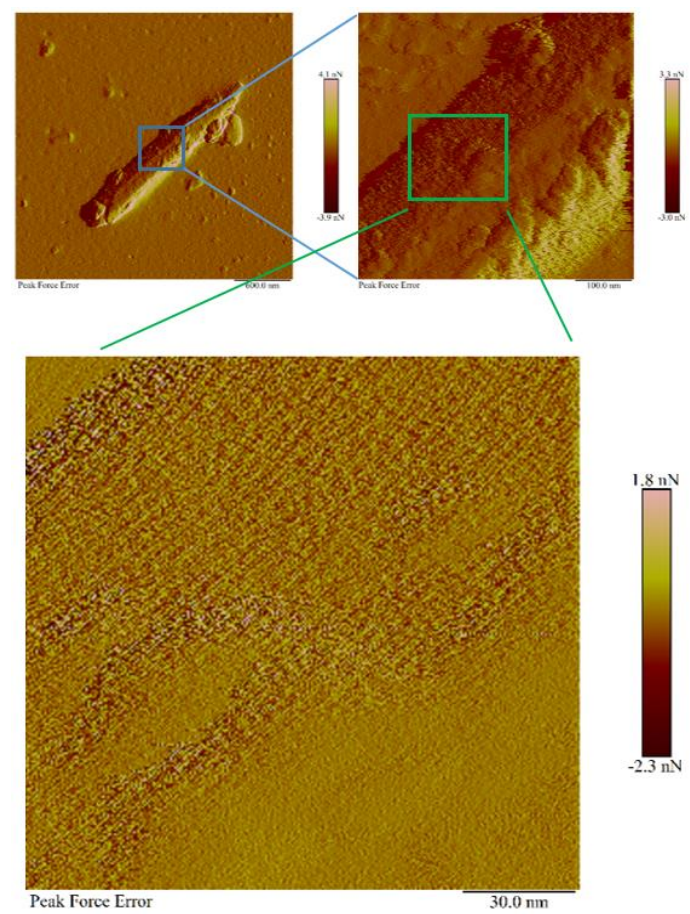

$\square$

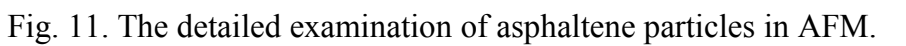

\subsection{The key role of asphaltenes}

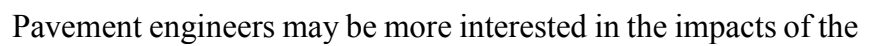

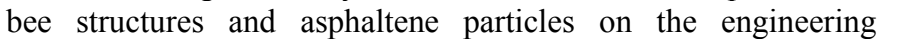

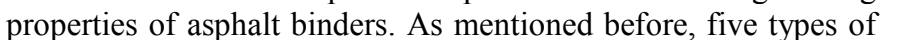

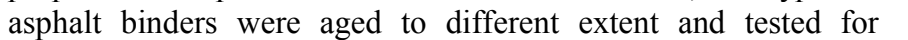

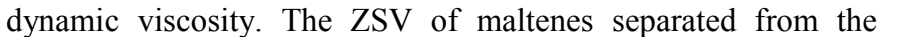

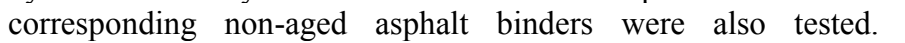

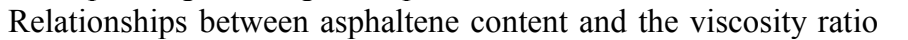

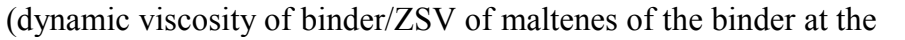

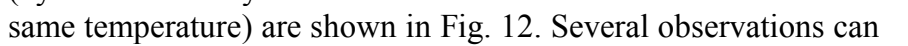

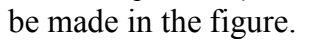

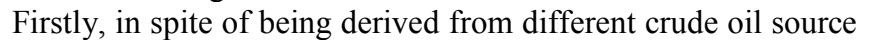
மாயா

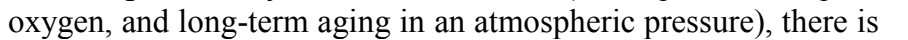

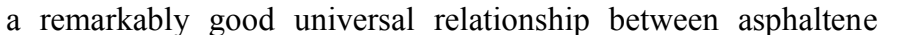

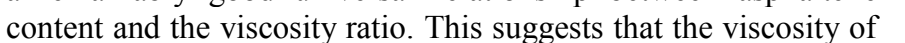

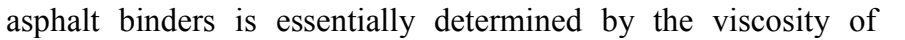

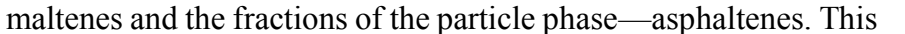

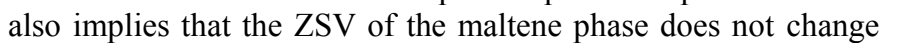

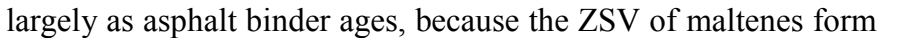

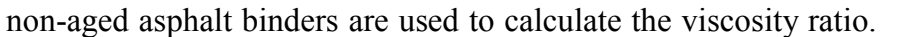

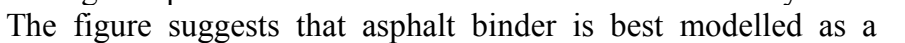

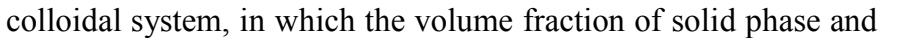

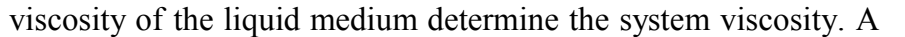

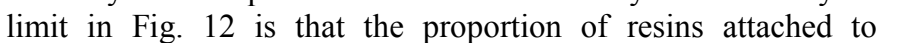

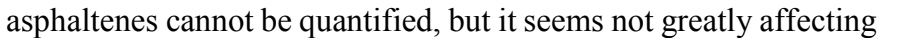

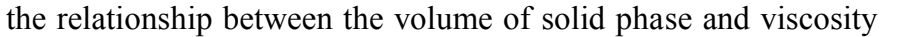
पाणाण

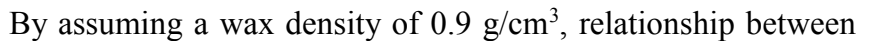

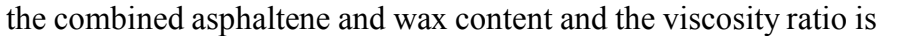

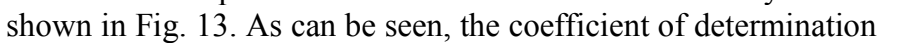

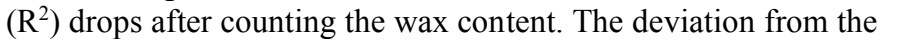

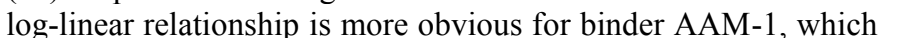

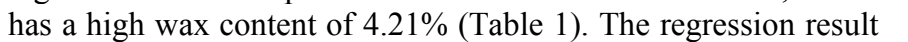

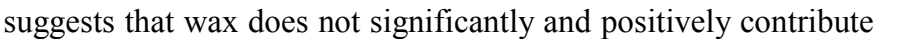

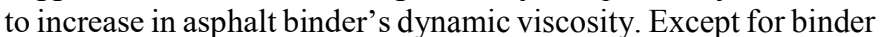

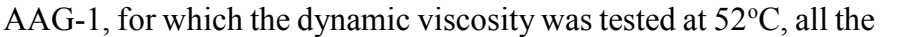

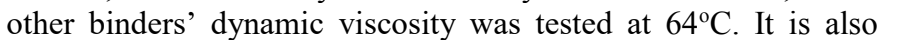

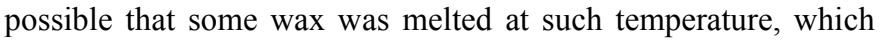

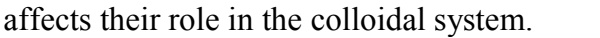

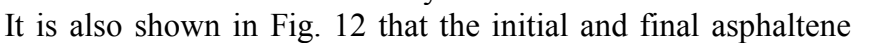

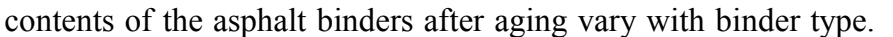

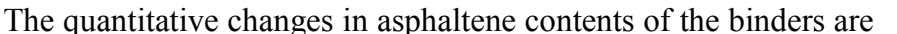

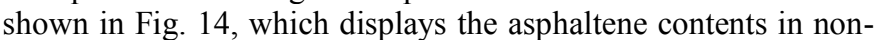

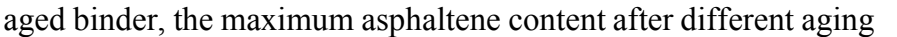

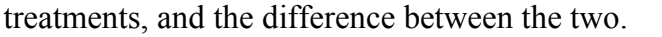

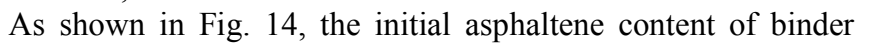

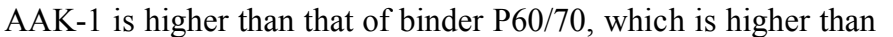

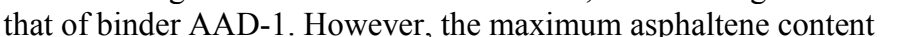

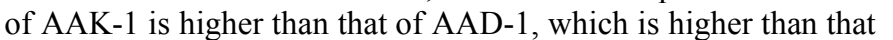

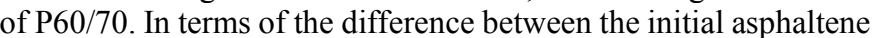

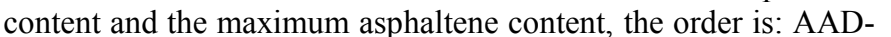

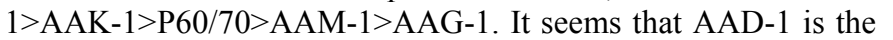

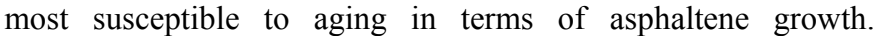

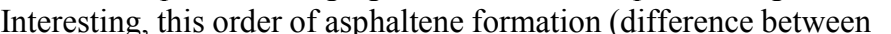
पाயா

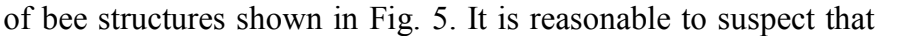

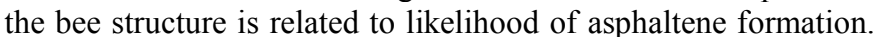

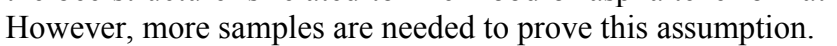

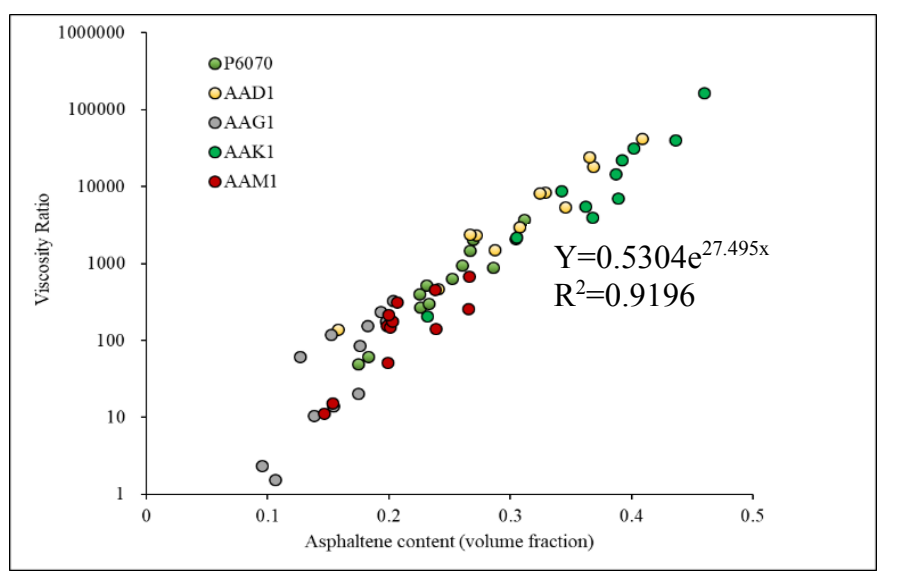

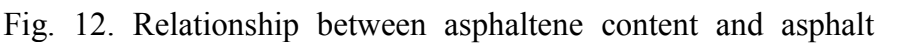
binders' viscosity ratios. $\square$

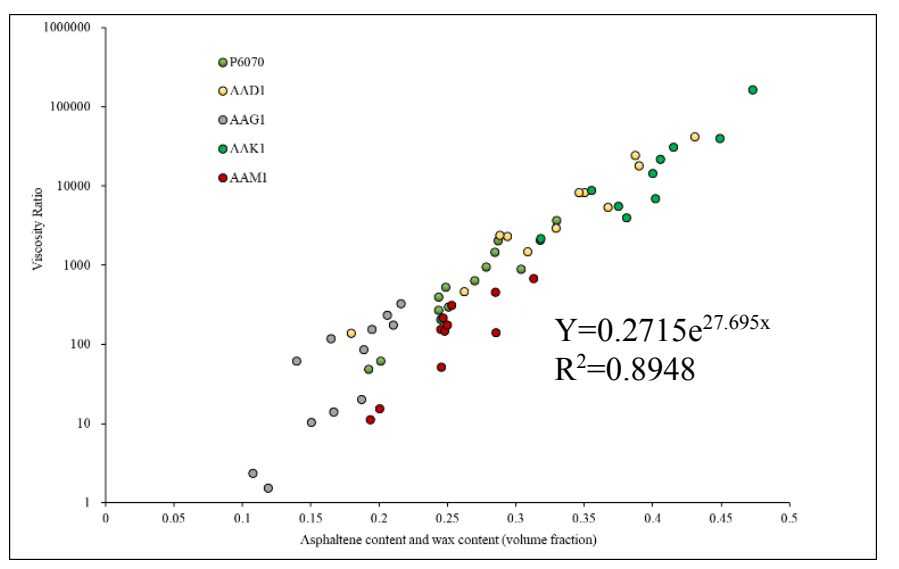

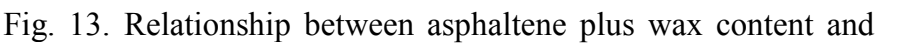
asphalt binders' viscosity ratios. $\square$ 


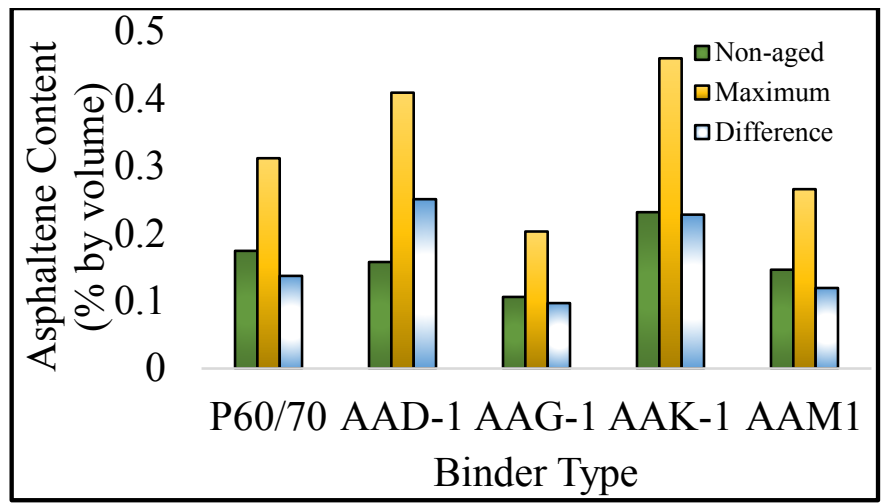

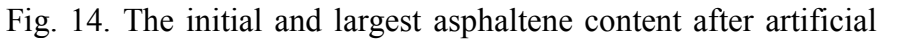
पाणाण

\section{Summary and conclusion}

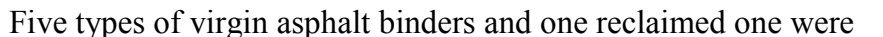

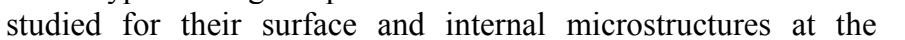

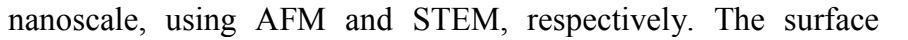

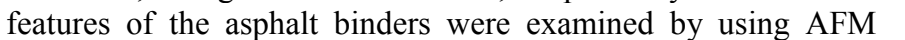

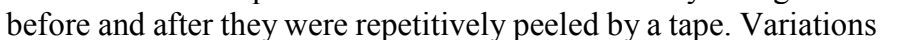

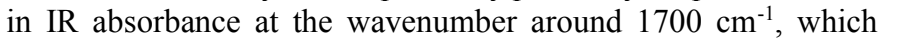

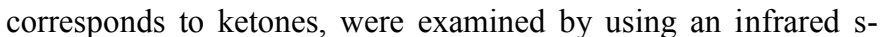

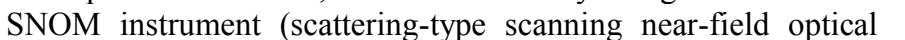

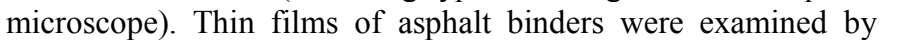

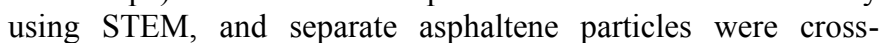

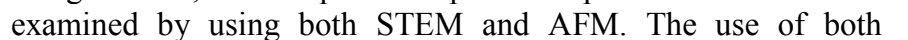

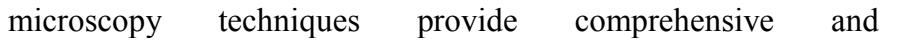

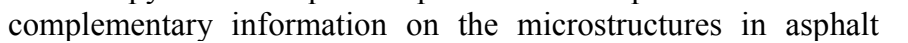

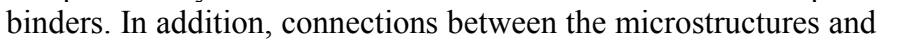
binder's physicochemical properties were evaluated. The

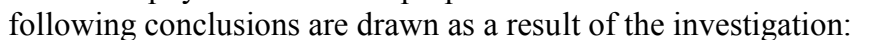

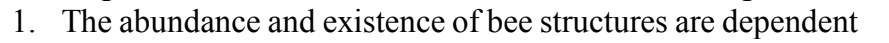

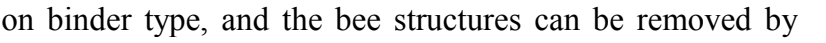

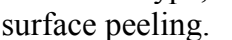

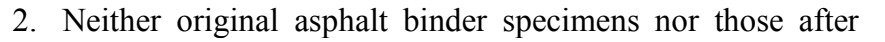

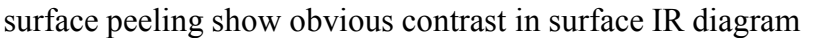

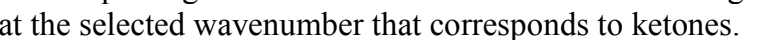

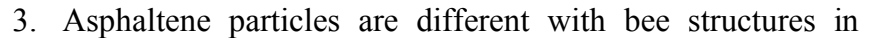

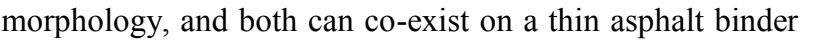
घाणाएा

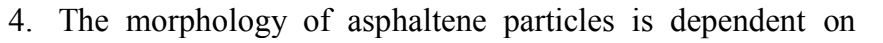

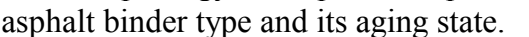

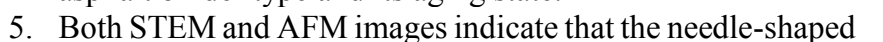

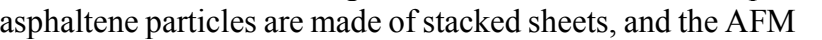

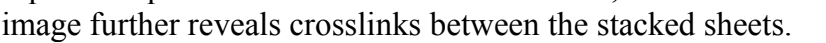

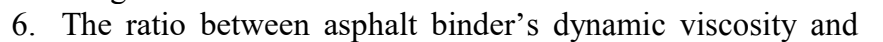
maltenes' zero shear viscosity is mainly determined by

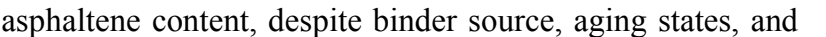

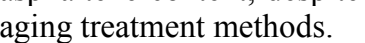

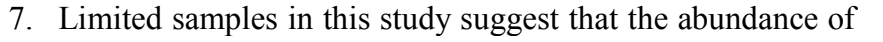

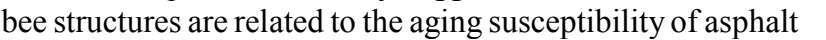

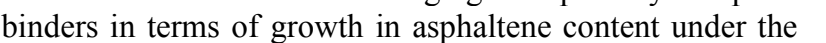

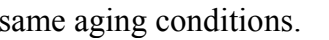

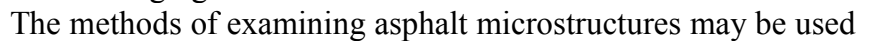

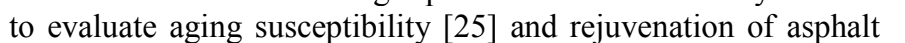
पणाप⿴囗十ा The identified relationship between binders'

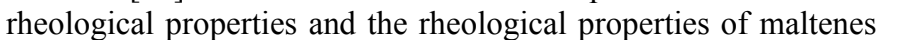

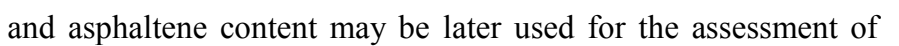

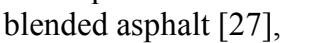

\section{Acknowledgment}

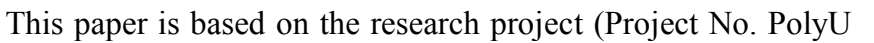

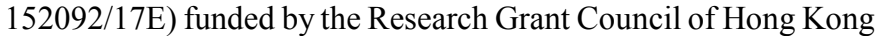

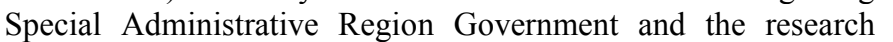

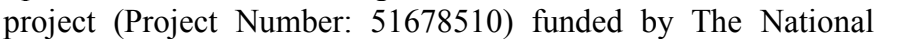

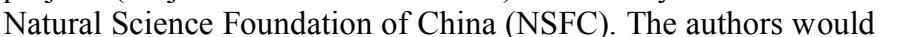

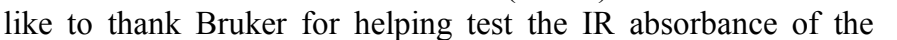
पापाणाए

$\square$

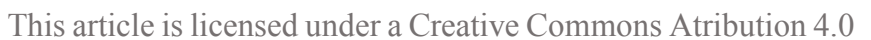

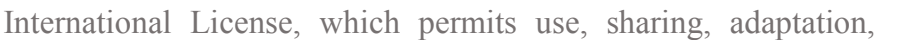

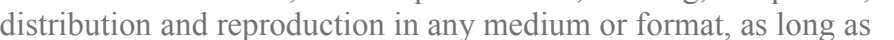

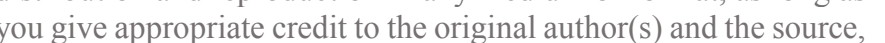

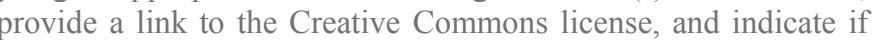

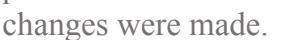

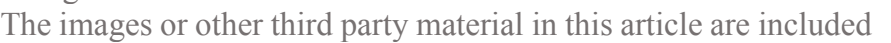
पण

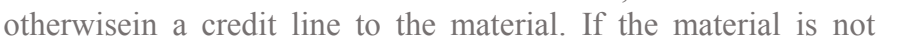

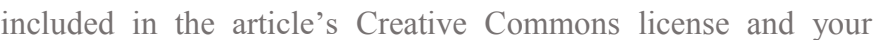

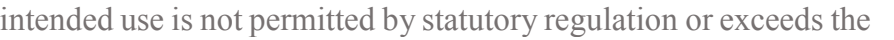

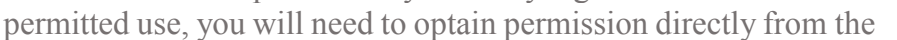

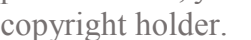

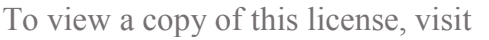

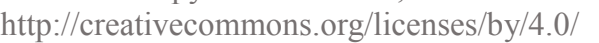

\section{Reference}

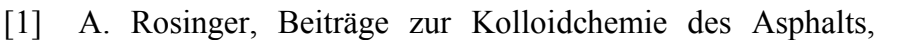

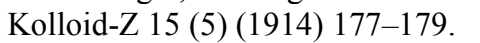

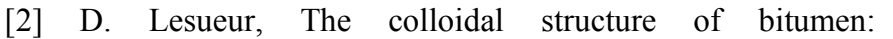

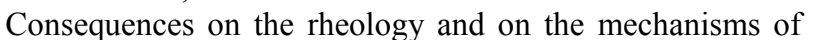

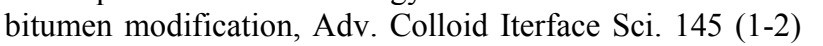

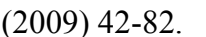

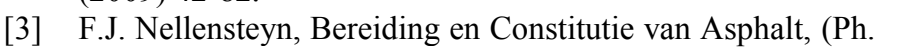

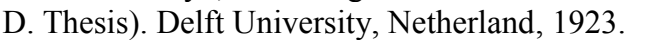

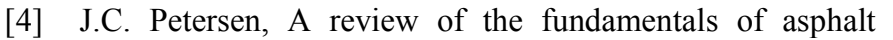

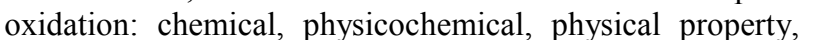

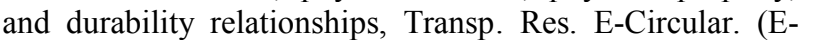

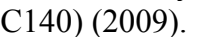

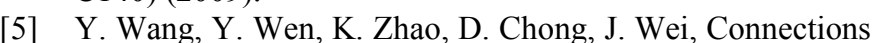

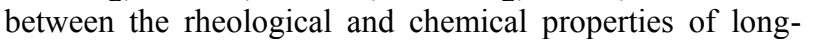
ए $\square 11\|1\|$

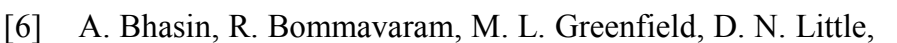

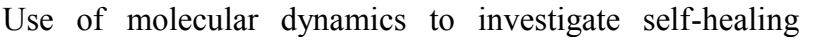

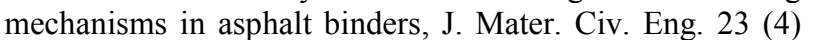
एातापातामा

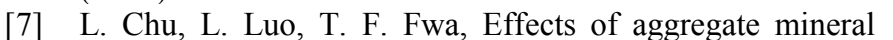

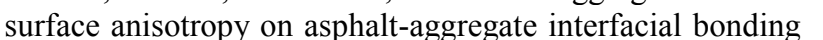

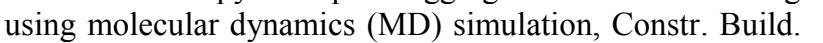

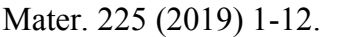

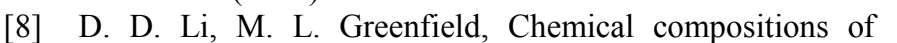

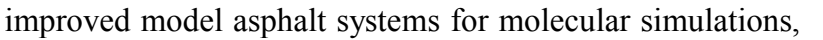

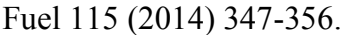

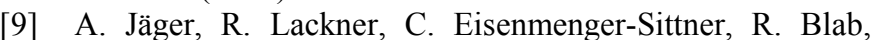

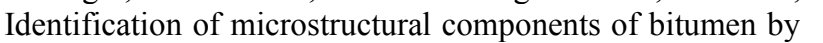

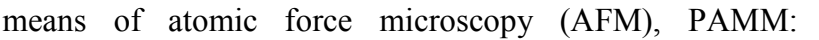




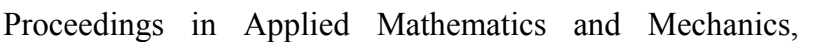

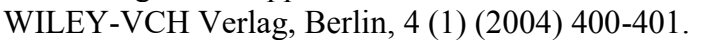

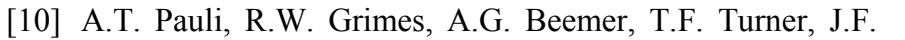

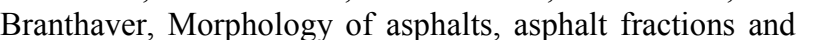

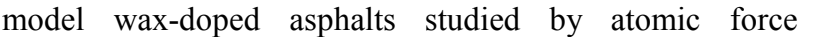

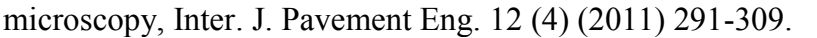

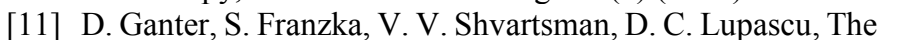

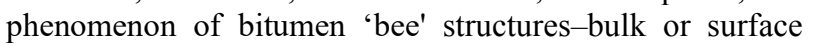

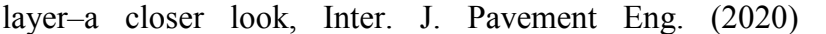

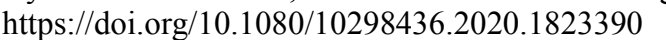

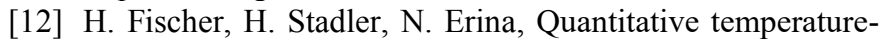

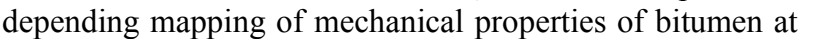

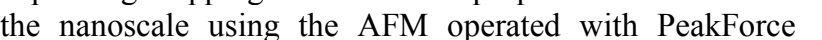

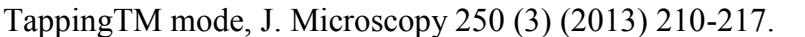

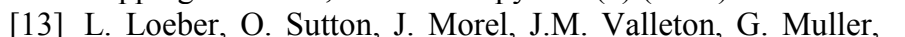

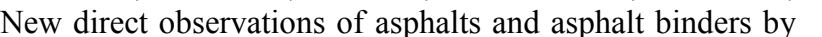

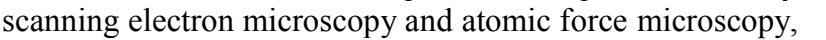

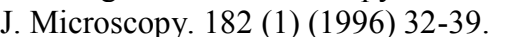

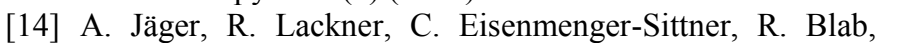

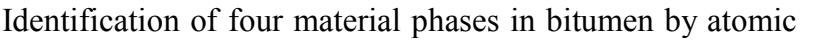

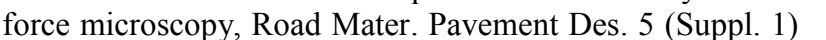
एणाएणाणए

एम

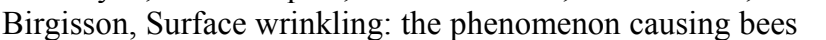

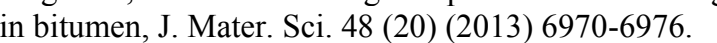

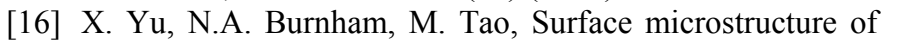

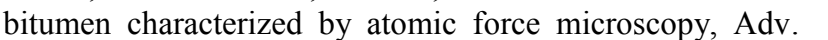

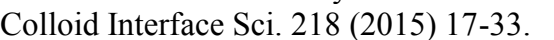

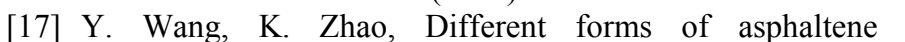

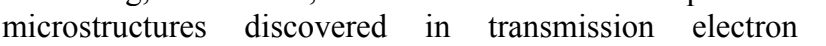

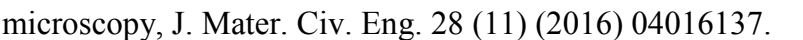

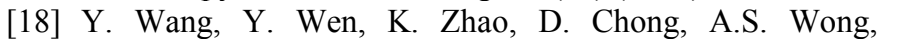

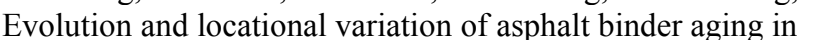

$\square$

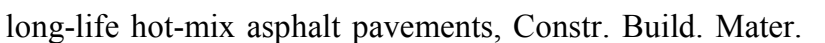

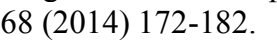

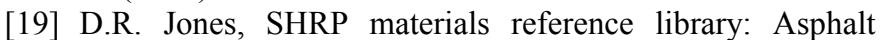

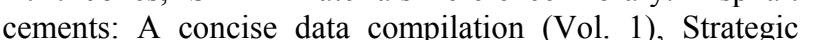

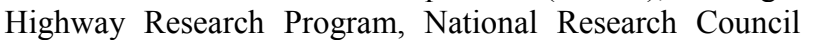

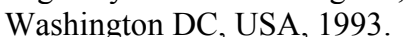

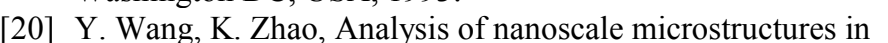

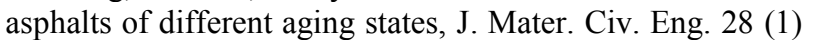
एणामाणामाप

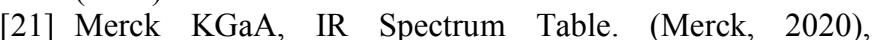

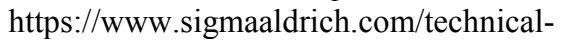

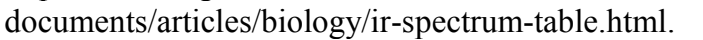

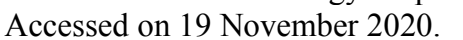

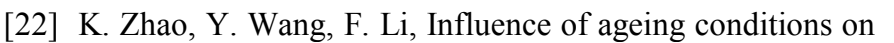

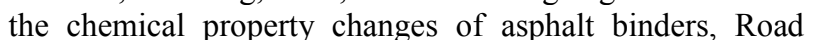

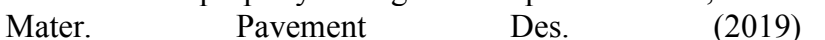

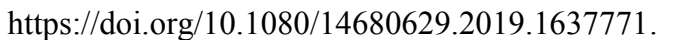

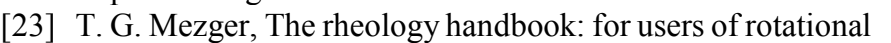

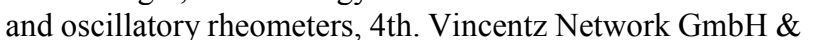

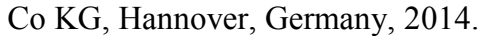

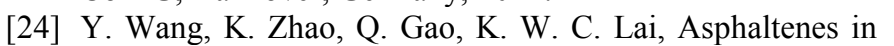

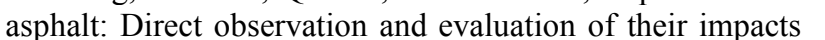

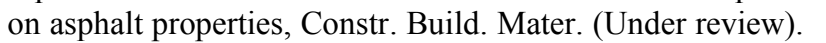
पा1ामाण

घम

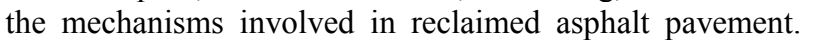

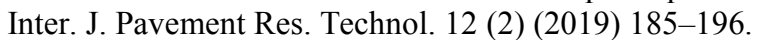

एम

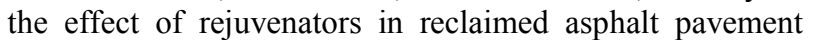

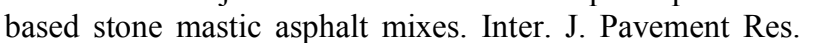

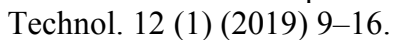

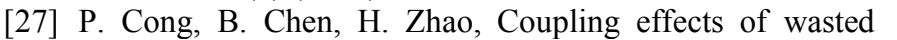

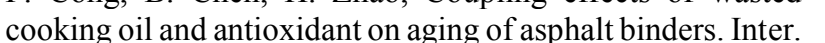

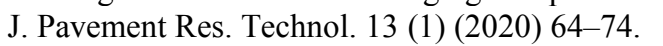

